\title{
Multi-objective economic operation of modern power system considering weather variability using adaptive cuckoo search algorithm
}

\author{
K. V. Kumar Kavuturu ${ }^{1 *}$ and P. V. R. L. Narasimham²
}

\section{${ }^{*}$ Correspondence:}

vasishta.kavuturu@gmail.com

${ }^{1}$ Research Scholar, Department of Electrical and Electronics Engineering, JNTUK, Kakinada, Andhra Pradesh 533003, India Full list of author information is available at the end of the article

\begin{abstract}
Currently, most of the power systems are being integrated with flexible AC transmission system devices and renewable energy sources for operating with enhanced security margins and balancing the increasing demand cost-effectively. On the other side, the trend of increasing global warming and extremely changing weather conditions is continuing across the world. Under this scenario, it is essential to realize their effect on various power system components and its economic operation. In this paper, the parameters namely resistance of the transmission line/transformer, load and solar photovoltaic generation are modeled considering ambient temperature effect. Later, economic schedule under changing weather conditions is proposed for attaining multi-objectives simultaneously like total operating cost of conventional energy, real power loss, average voltage collapse point indicator index and average voltage deviation index. Also, the dispatchable problems in the transmission system and various practical operating constraints are handled via optimally setting the parameters of optimal unified power flow controller. The optimization problem is solved using adaptive cuckoo search algorithm (ACSA), in which a dynamically increasing switching parameter in a power of three is adopted for adjusting the random walk between local optima and global optima. The superiority of the proposed ACSA in solving the multiobjective, nonlinear complex optimization problem over basic CSA and particle swarm optimization, chicken swarm optimization and flower pollination algorithm is presented by illustrating various case studies on standard IEEE 14, 30 and 118-bus test systems.
\end{abstract}

Keywords: Adaptive cuckoo search algorithm, Economic schedule, Optimal unified power flow controller, Photovoltaic generation, Weather variability

\section{Introduction}

The energy requirement has been increased significantly across the world. For an instant, as per 'executive summary on power sector-March 2019 by Central Electricity Authority (CEA), energy requirement across India is projected as 2.11\% raise for March 2019 (108,665 MU) as compared with March 2018 (106,420 MU). Under this scenario, integration of renewable energy $(\mathrm{RE})$ in power system becomes one of the counter measures

\section{Springer Open}

(c) The Author(s) 2020. This article is licensed under a Creative Commons Attribution 4.0 International License, which permits use, sharing, adaptation, distribution and reproduction in any medium or format, as long as you give appropriate credit to the original author(s) and the source, provide a link to the Creative Commons licence, and indicate if changes were made. The images or other third party material in this article are included in the article's Creative Commons licence, unless indicated otherwise in a credit line to the material. If material is not included in the article's Creative Commons licence and your intended use is not permitted by statutory regulation or exceeds the permitted use, you will need to obtain permission directly from the copyright holder. To view a copy of this licence, visit http://creativeco mmons.org/licenses/by/4.0/. 
for both increasing electricity demand as well as global warming across the world [1, 2]. According to the International Renewable Energy Agency (IRENA) statics report released in March 2019, the total RE integration in 2018 has been reached to 2364.4 GW including off-grid across the world [3]. Among various types of RE sources [4], solar photovoltaic (PV) has become the most attractive technology even at the end-user side. As compared to the fossil fuel-based conventional energy (CE), the RE sources have various advantages like (1) reduced active power losses, (2) improved voltage profile, (3) increased overall energy efficiency, (4) congestion relief across the system elements, (5) potential increase in service quality to the end-customers, etc., however, their intermittency nature of RE sources needs to be addressed potentially for avoiding the possible operational and controlling issues [5]. On the other side, the non-expanding transmission systems and various uncertainties have been resulted various power system blackouts across the world $[6,7]$. In order to overcome these potential problems, the flexible ac transmission system (FACTS) devices in power systems have been introduced and become one of the promising solutions for stability enhancement, loadability enhancement, loss minimization and economic operation, etc., as well as to prevent various likelihood uncertainties in real-time operation of many power systems across the world [8]. A comprehensive survey on different types of FACTS devices proposed for stability enhancement can be found in [9] and for transmission system security management in deregulation era can be found in $[10,11]$. In flip, the raising scenario of global warming becomes one of the major concerns in planning studies of almost all the sectors and particularly reducing the carbon emission in electric generation become more important in power system operation. According to 'climate change scenarios for India', the surface temperature is projected to increase as much as $3-4{ }^{\circ} \mathrm{C}$ toward the end of the twentyfirst century. Similarly, as per India Meteorological Department (IMD) reports, January 2019 , annual mean temperature during 1901-2018 showed an increasing trend of $0.6{ }^{\circ} \mathrm{C}$ per 100 years. Under this scenario, it is essential to consider the impact of ambient temperature on power system operating condition, which has been neglected almost in all the works in the literature. Hence, consideration of RES uncertainty, change of ambient temperature and FACTS controls in economic operation of modern power systems cannot be negligible.

Economic load dispatch (ELD) problem is one of the fundamental optimization problems toward minimum generation cost in power system operation. Traditionally, optimal power flow (OPF) is in practice for determining the solution of ELD problem without compromising in various operational constraints [12]. Apart from the conventional approaches like lambda-iterative method, the base point and participation factors method and the gradient methods, many authors have been focused on various meta-heuristic algorithm-based approaches in recent times for solving the OPF considering FACTS devices and/or uncertainty in power generation by RE generation sources. In [13], a hybrid algorithm moth swarm algorithm (MSA) and gravitational search algorithm (MSA-GSA) is proposed for OPF considering wind power. In [14], a modified version of the moth swarm algorithm (MMSA)-based OPF is proposed for handling the stochastic nature of wind generation. In [15], OPF based problem is solved by using a modified hybrid particle swarm optimization and gravitational search algorithm (PSO-GSA) with chaotic maps approach considering stochastic 
nature of wind generation and FACTS devices such as thyristor-controlled series capacitor (TCSC) and thyristor-controlled phase shifter (TCPS). In [16], distributed-FACTS (D-FACTS) and FACTS devices are proposed for attaining the substantial cost savings by assuring the congestion relief in transmission system as well as minimum RE power curtailment in the competitive electricity market environment. In [17], a novel tree-seed algorithm (TSA) is proposed for solving the OPF problem considering various continuous and discrete control variables. In [18], modified JAYA (MJAYA) algorithm is proposed for multi-objective OPF problem considering operating cost, emission, real power loss and voltage profile in the presence of different RE sources in the network. In [19], a hybrid algorithm using dragonfly algorithm (DA) and aging particle swarm optimization (APSO) is proposed for OPF considering wind power. In [20], novel improved social spider optimization (NISSO) algorithm is proposed for solving the OPF with various single-objective functions like operating cost, real power loss, total emission, voltage deviation and stability index. A modified sinecosine algorithm (MSCA) with Levy flights is proposed for solving single-objective OPF problem [21]. Considering uncertainties due to wind power and various factors in the grid, evidence theory (ET) and extended affine arithmetic (AA) are employed for OPF problem [22]. In [23], a three-stage real-time OPF (RTOPF) strategy is proposed to handle the error in forecasting the RE and demand loads. In [24], a modified moth swarm algorithm with an arithmetic crossover (MSA-AC) is proposed for solving the constrained optimization and OPF problem. In [25], optimal location of distribution generation (DG) is handled simultaneously while solving the conventional OPF problem over the $24 \mathrm{~h}$ of the day using sun flower optimization (SFO) algorithm. In [26], particle swarm optimization with an aging leader and challengers algorithm (ALC-PSO) is proposed for solving the different single-objective OPF problems considering thyristor-controlled series capacitor (TCSC) and thyristor-controlled phase shifter (TCPS). In [27], minimization of congestion cost under different contingency conditions is solved using symbiotic organisms search (SOS) algorithm. In [28], various single and multi-objective functions with different combinations of single-objective functions are solved using backtracking search optimization algorithm (BSA). In [29], a tri-population based DE-PSO-DE optimization algorithm using differential evolution (DE) and particle swarm optimization (PSO) is proposed for solving the economic load dispatch problem considering operating cost, real power loss, ramp rate and spinning reserve constraints. In [30], power system security enhancement via fuzzy harmony search algorithm (FHSA)-based OPF is proposed considering TCSC at pre-determined optimal location, which determined using line overload sensitivity index (LOSI). In [31], symbiotic organisms search (SOS) algorithm is proposed for solving the OPF considering thyristor-controlled series capacitor (TCSC) and thyristor-controlled phase shifter (TCPS). The objective functions include operating cost, valve-point loading effect, real power loss and combined economic and environmental cost. In [32], the OPF problem is solved using modified BAT optimization problem in the presence of interline power flow controller (IPFC) considering dynamic loading conditions. In [33], the design aspects of AC-DC smart micro-grid considering availability and cost of equipments is presented. The authors proposed the hybrid micro-grid with wind, solar and battery bank systems and optimized the economics 
of modern grid using multi-objective particle swarm optimization (MOPSO). In [34], the power quality issues with variable RESs have been mitigated using FACTS devices considering technical and economical aspects of power system.

From the above reviewed literature, it can be said that the OPF framework is used to solve a wide range of single- and/or multi-objectives (namely cost, voltage profile, voltage stability, loadability, security or congestion, multi-fuels, valve-point loading and effect emission) considering different types of FACTS devices and uncertainty in RES generation, load, contingencies and different operational equal and unequal constraints. Also, the OPF problem is solved with different heuristic algorithms effectively than conventional approaches like nonlinear quadratic programming [35], Newton [36] and interior-point [37] methods.

In recent times, consideration of environmental aspects in the economic operations and planning studies of power system engineering is getting attraction considerably. In $[38,39]$, the impact of weather changes on distribution system load profile and losses are addressed. In [40], ambient temperature effect on load and consequently distribution system performance is analyzed and improved via optimal allocation of capacitor banks. In [41], weather changes on transmission system parameters are highlighted through transient stability analysis. In $[42,43]$, the conventional NR power flow method is reformulated considering the impact of temperature on transmission system parameters. In [44], output characteristics of solar PV panels are analyzed under different weather conditions. In [45], the experimental investigations in Brighton in the southeast of the UK revealed that the solar PV system efficiency is reduced by $60 \%$ due to dusty or polluted climate. From these works, it can be concluded that the consideration of weather changes is also necessary in planning studies and for effective operation and control of power systems in the current as well as future scenario of increasing global warming and changing weather conditions [46]. Most importantly, it is also observed that the impact of weather changes on transmission system parameters, load profile, solar photovoltaic generation and consequently power system techno-economic operating condition is not addressed w.r.t. FACTS controls. Since OPF problem is nonlinear and complex in nature, it is easy to solve using heuristic approaches than non-heuristic approaches. But the heuristic approaches used in literature may not escape local optima while solving OPF with multi-objectives and many search variables. Hence, there is a need to reevaluate the performance of heuristic approaches by modifying the search process between local optima and global optima.

\section{Methods of work}

In light of the above introduction, ambient temperature effect-based load growth, photovoltaic (PV) generation and transmission system parameters are modeled and considered in the OPF framework in this paper. Also, optimal unified power flow controller (OUPFC) is allocated in the system and tuned its controlling parameters optimally for minimizing the multi-objective function with total generation cost of conventional energy (CE), real power losses, voltage deviation and proximity of voltage instability under different weather seasons. The multi-objective function is optimized using adaptive cuckoo search algorithm (ACSA). In the proposed ACSA, a dynamically increasing switching parameter in a power of three is adopted for adjusting the random walk 
between local optima and global optima [47]. The superiority of the proposed ACSA in solving the multi-objective, nonlinear complex optimization problem over basic cuckoo search algorithm (CSA), particle swarm optimization (PSO), chicken swarm optimization (CSO), flower pollination algorithm (FPA), grasshopper optimization algorithm (GHO), whale optimization algorithm (WOA) and ant lion optimization (ALO) is presented by illustrating various case studies on standard IEEE 14, 30, and 118-bus test systems.

\section{Related concepts and modeling}

In this section, the power injection modeling (PIM) of OUPFC device and voltage collapse point indicator (VCPI)-based strategy for determining its optimal location is explained. Also, the ambient temperature impact on PV system generation, system loading conditions and transmission line parameters are explained.

\section{Optimal unified power flow controller}

Among the FACTS devices, the second-generation FACTS devices like unified power flow controller (UPFC) and interline power flow controller (IPFC) have wide range of applications in power system operation and control. UPFC is a versatile device and can be able to control the power flow parameters of a line (i.e., bus voltage, phase angle and line reactance) individually or in combination. IPFC is able to control power flows in multiple transmission lines at a substation simultaneously or consecutively. The advanced version of UPFC by integrating conventional phase shift transformer (PST) is proposed as optimal unified power flow controller (OUPFC) with its operating features and steady-state mathematical modeling [49].

The basic difference between UPFC and OUPFC can be understood by comparing Fig. 1a, b, respectively. Generally, UPFC consists of shunt converter coupled with excitation transformer and series converter coupled with injecting transformer as shown in Fig. 1a. A similar configuration can be found in Fig. 1b for OUPFC except the transformers with triple winding. The secondary windings of these two transformers are connected by a phase shift transformer (PST) which can be controlled by static/mechanical switches to inject a voltage with fixed phase into the transmission line. On the other side, the tertiary windings of these two transformers are used for conventional UPFC configuration.
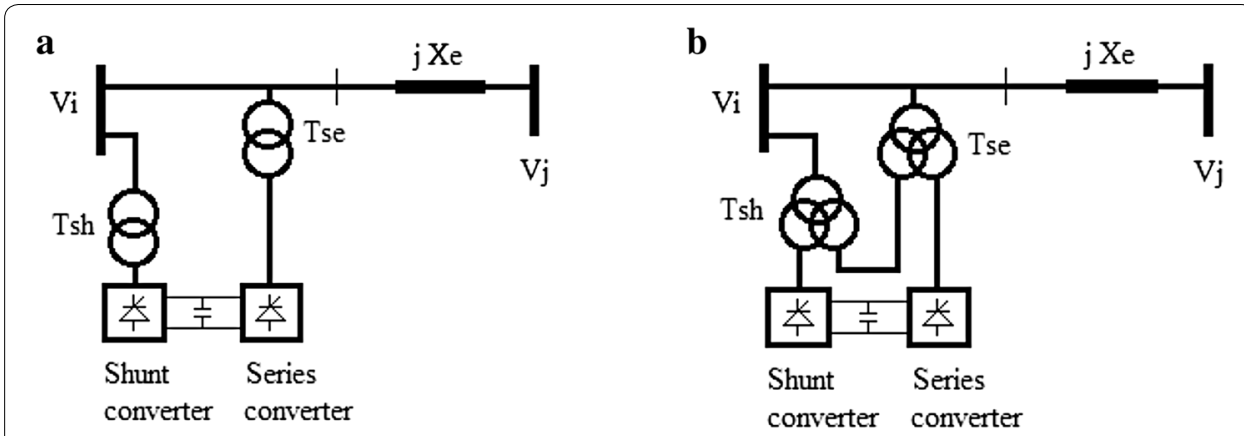

Fig. 1 a Single-line diagram of UPFC connected between bus-i and bus-j. b Single-line diagram of OUPFC connected between bus-i and bus-j 
According to PIM of OUPFC, the injection powers at bus $i$ and bus $j$ are given as follows:

$$
\begin{aligned}
P_{i n j, i}= & -b_{s e} a V_{i} V_{j} \sin \left(\theta_{i}-\theta_{j}+\alpha_{\mathrm{pst}}\right) \\
& -b_{s e} r V_{i} V_{j} \sin \left(\theta_{i}-\theta_{j}+\gamma_{\mathrm{upsc}}\right) \\
P_{i n j, j}= & -P_{i n j, i} \\
Q_{i n j, i}= & -b_{s e} V_{i}^{2}\left(a^{2}+r^{2}\right)-2 b_{s e} a r V_{i}^{2} \cos \left(\alpha_{\mathrm{pst}}-\gamma_{\mathrm{upsc}}\right) \\
& -2 b_{s e} V_{i}^{2}\left\{a \cos \left(\alpha_{\mathrm{pst}}\right)+r \cos \left(\gamma_{\mathrm{upsc}}\right)\right\} \\
& +b_{s e} V_{i} V_{j}\left\{\begin{array}{c}
a \cos \left(\theta_{i}-\theta_{j}+\alpha_{\mathrm{pst}}\right) \\
+r \cos \left(\theta_{i}-\theta_{j}+\gamma_{\mathrm{upsc}}\right)
\end{array}\right\} \\
Q_{i n j, j}= & b_{s e} V_{i} V_{j}\left\{\begin{array}{c}
a \cos \left(\theta_{i}-\theta_{j}+\alpha_{\mathrm{pst}}\right) \\
+r \cos \left(\theta_{i}-\theta_{j}+\gamma_{\mathrm{upsc}}\right)
\end{array}\right\}
\end{aligned}
$$

where $V_{i}$ and $V_{j}$ are the magnitudes and $\theta_{i}$ and $\theta_{j}$ are the voltage angles at bus- $i$ and bus$j$, respectively. Here, $b_{s e}=1 / x_{s e}$, where $x_{s e}$ is the total reactance of the circuit includes transmission line and injecting transformer reactance, $r$ is the radius of the UPFC operating region and $\gamma_{\text {upfc }}$ is the phase angle of the UPFC; $a$ is the ration between injection voltage of PST and exciting transformer voltage and $\alpha_{\text {pst }}$ is the phase angle of PST.

\section{Optimal location of OUPFC}

All the FACTS devices have their own mode of operation and designed to control some specific attributes, the location should be optimized to get better results. From the literature, the solution approaches for optimal location of FACTS devices problem can be classified into three categories like direct, strategic and optimization problem-based approaches. In direct approaches, the impact on a specific parameter is analyzed directly by integrating FACTS devices at a selected location. Based on the significant impact on a specified parameter, the locations are further ranked to finalize optimal location. The computational effort involved in direct approaches can overcome by using strategic approaches. These approaches are basically based on sensitivity analysis with control variables in load flow study. By analyzing the impact of change in control variable on a specific attribute, the location of FACTS devices is finalized. Similarly, various heuristic approaches which have been widely used for FACTS location and sizing can be found in $[50,51]$.

Based on maximum power transfer, voltage collapse point indicator (VCPI) is proposed for assessing static voltage stability of the power system [52]. Consider a transmission line connected between bus-s (sending end) and bus- $r$ (receiving end) having impedance $Z_{\mathrm{sr}}=R_{\mathrm{sr}}+j X_{\mathrm{sr}}$. For a connected load $P_{r}+j Q_{r}$ at bus- $r$, VCPI is defined as 'the ratio between real power connected at receiving end $\left(P_{\mathrm{r}}\right)$ and maximum power $\left(P_{\mathrm{r}, \max }\right)$ that can be loadable at critically stable operating point' and is given mathematically in (5). 


$$
\begin{aligned}
& \mathrm{VCPI}_{\mathrm{sr}}=P_{\mathrm{r}} / P_{\mathrm{r}, \mathrm{max}} \\
& P_{\mathrm{r}, \max }=V_{\mathrm{s}}^{2} \cos \phi_{r} /\left\{4 Z_{\mathrm{sr}} \cos ^{2}\left[\left(\theta_{z}-\phi_{\mathrm{r}}\right) / 2\right]\right\} \\
& \theta_{z}=\tan ^{-1}\left(X_{\mathrm{rs}} / R_{\mathrm{rs}}\right) \text { and } \phi_{r}=\tan ^{-1}\left(Q_{\mathrm{r}} / P_{\mathrm{r}}\right)
\end{aligned}
$$

where $V_{\mathrm{s}}$ is the sending end bus voltage; $\varnothing_{\mathrm{r}}$ is the load power factor; $\varnothing_{z}$ is the impedance angle.

According to VCPI, the line which has highest value can be treated as critical line due to lowest maximum transfer capability. For a specified operating condition, the lines are ranked as VCPI values and top ranked line is chosen for OUPFC integration.

\section{Modeling of solar PV system}

The power output of a solar PV module can be found as a function of global solar irradiance and ambient temperature using Eq. (8) [53].

$$
P_{\mathrm{PV}(t)}=\mathrm{FF} \cdot\left(I_{\mathrm{sc}} \cdot \frac{G_{\mathrm{t}}}{G_{\mathrm{ref}}}\right) \cdot\left(V_{\mathrm{oc}} \cdot \frac{\ln \left(P_{1} \cdot G_{t}\right)}{\ln \left(P_{1} \cdot G_{\mathrm{ref}}\right)} \cdot \frac{T_{\mathrm{ref}}}{T_{\mathrm{a}}}\right)
$$

where

$$
\mathrm{FF}=\frac{P_{\mathrm{max}, \mathrm{m}}}{V_{\mathrm{oc}} \cdot I_{\mathrm{sc}}}=\frac{V_{\mathrm{mmp}} \cdot I_{\mathrm{mpp}}}{V_{\mathrm{oc}} \cdot I_{\mathrm{sc}}}, \quad P_{1}=\left(\frac{I_{\mathrm{sc}}}{G_{t}}\right)
$$

Correspondingly, the output of a PV system is modeled in proportional to the module output as given in Eq. (10).

$$
P_{g, j}=\mathrm{IC} \mathrm{PV} \times \frac{P_{\mathrm{PV}(t)}}{P_{\mathrm{PV}(\mathrm{ref})}}
$$

Here, it is assumed that the PV systems are integrated to the grid via grid-compatible inverter, by which voltage and frequency regulation can be done effectively at the point of common coupling (PCC).

The impact of PV generation at a load bus if finally realized in terms of reduced load as given by:

$$
P_{d, j}^{\text {new }}=\left(P_{d, j}-P_{g, j}\right)
$$

Correspondingly, there is a change in power factor $\left(\cos \phi_{1}\right)$ of that load bus and consequently, $\tan \left(\varnothing_{1}\right)$ is given by:

$$
\tan \left(\cos ^{-1}\left(\phi_{1}\right)\right)=Q_{d, j} / P_{d, j}^{n e w}
$$

In order to maintain power factor at the desire value $\left(\cos \left(\varnothing_{1}\right)\right)$, the required reactive power to be supplied by PV inverter is given by: 


$$
Q_{i n, j}=\tan \left(\cos ^{-1}\left(\phi_{2}\right)\right)-\tan \left(\cos ^{-1}\left(\phi_{1}\right)\right)
$$

The new reactive loading condition at PV source bus- $j$ is finally given by:

$$
Q_{d, j}^{\text {new }}=\left(Q_{d, j}-Q_{\text {in }, j}\right)
$$

where $P_{\max , \mathrm{m}}$ is the module maximum power under standard testing conditions (STC), $V_{\mathrm{mmp}}$ and $I_{\mathrm{mmp}}$ are the corresponding voltage and currents, respectively; $V_{\mathrm{oc}}$ and $I_{\mathrm{sc}}$ are the open-circuit voltage and short-circuit currents, respectively; $G_{\text {ref }}$ and $T_{\text {ref }}$ are the global irradiance and temperature at STC, respectively; $G_{t}$ and $T_{a}$ are the actual global irradiance and ambient temperature, respectively; $\mathrm{IC}_{\mathrm{PV}}$ is the installed capacity of the PV system in MW; $P_{\mathrm{PV}(\mathrm{ref})}$ and $P_{\mathrm{PV}(\mathrm{t})}$ are the module output at reference and ambient temperature, respectively; $P_{g, j}$ is the real power generation of a PV system at ambient temperature in MW; $S_{\text {in }}$ is the inverter MVA rating; and $Q_{\mathrm{in}, j}$ is the MVAr generation by the PV inverter; $P_{d, j}$ and $Q_{d, j}$ are the real and reactive power loads at bus-j, respectively.

\section{Temperature dependency load modeling}

The increased load demand due to raise in ambient temperature can be modeled as proposed [40] by:

$$
P_{d\left(T_{a}\right)}=m \times T_{a}+P_{d(\text { base })}
$$

where $P_{d \text { (base) }}$ and $P_{d(\text { Ta })}$ are the system load in MW at base case and ambient temperature, respectively; $T_{\mathrm{a}}$ is the ambient temperature in degree Celsius; $m$ is the slope of increasing power consumption per one degree Celsius.

\section{Thermal modeling of transmission line resistance}

The change in transmission line resistance due to change in ambient temperature can be modeled as follows [42]:

$$
R\left(T_{\mathrm{a}}\right)=R\left(T_{\text {ref }}\right) \times \frac{T_{\mathrm{a}}+T_{\mathrm{c}}}{T_{\text {ref }}+T_{\mathrm{c}}}
$$

where $R\left(T_{\text {ref }}\right)$ and $R\left(T_{\mathrm{a}}\right)$ are the transmission line resistances at reference $\left(T_{\mathrm{ref}}\right)$ and ambient temperature $\left(T_{\mathrm{a}}\right)$, respectively; $T_{\mathrm{c}}$ is the temperature constant depends on type of conductor material.

\section{Problem formulation}

The OPF problem can be formulated for single or multiple objectives by having a set of equal and inequal operating constraints.

\section{Overall objective function}

The overall objective function is formulated with multi-objectives to minimize total operating cost at CE sources $\left(f_{1}\right)$, real power losses $\left(f_{2}\right)$, average voltage collapse point indicator index $\left(f_{3}\right)$ and average voltage deviation $\left(f_{4}\right)$ simultaneously. The objective function expressed as, 


$$
\mathrm{OF}=\min \left(f_{1}+f_{2}+f_{3}+f_{4}\right)
$$

The individual objective functions are expressed in Eqs. (16)-(19) for real power loss, average line stability index and average voltage deviation index, respectively.

$$
\begin{aligned}
f_{1} & =\mathrm{C}_{T}\left(P_{g}\right)=\sum_{i=1}^{n C E}\left(a_{i} P_{g i}^{2}+b_{i} P_{g i}+c_{i}\right) \\
f_{2} & =P_{\text {loss }}=\sum_{k=1}^{\mathrm{nl}} I_{k}^{2} r_{k} \\
& =\sum_{i=1}^{\mathrm{nb}} \sum_{\substack{j=1 \\
j \neq i}}^{\mathrm{nb}}\left\{Y_{i i} \cos \theta_{i i}\left[V_{i}^{2}+V_{j}^{2}-2 V_{i} V_{j} \cos \left(\delta_{i}-\delta_{j}\right)\right]\right\} \\
f_{3} & =\mathrm{AVCPI}=\frac{1}{n l} \sum_{k=1}^{n l} \mathrm{VCPI}_{k} \\
f_{4} & =\mathrm{AVDI}=\frac{1}{\mathrm{nb}} \sum_{i=1}^{\mathrm{nb}}\left(\frac{\left|V_{i, \mathrm{ref}}\right|-\left|V_{i}\right|}{\left|V_{i, \mathrm{ref}}\right|}\right)^{2}
\end{aligned}
$$

where $a_{i}, b_{i}$ and $c_{i}$ are the cost coefficients of CE sources; $P_{g i}$ is power generation at CE bus $0.00 i ;\left|V_{i \text {,ref }}\right|$ and $\left|V_{i}\right|$ are the reference voltage magnitude and actual voltage magnitude for a particular operating condition, respectively; $n \mathrm{CE}, \mathrm{nb}$ and $\mathrm{nl}$ are the number of CE generator buses, total buses in the system and number of lines, respectively; $k$ is an index for the line connects between buses $i$ and $j ; r_{k}$ and $I_{k}$ are the resistance of line $k$ and current through it, respectively; $Y_{i i}$ and $\theta_{i j}$ are the shunt admittance at bus $i$ and its angle, respectively; $V_{i}$ and $V_{j}$ and $\delta_{i} \& \delta_{j}$ are the voltage magnitudes and their angles at buses $i$ and $j$, respectively.

\section{Operational constraints}

The overall objective function expressed in Eq. (15) is subjected to the following equality constraints (22)-(25) and inequality constraints (26)-(32).

Power flow equations corresponding to both real and reactive power balance equations are the equality constraints that can be written, for all the buses expect OUPFC incident buses, as

$$
\begin{aligned}
& P_{i}=P_{g i}-P_{d i(t)}=\sum_{k=1}^{\mathrm{nb}}\left|V_{i}\right|\left|V_{k}\right|\left|Y_{i k}\right| \cos \left(\theta_{i k}-\delta_{i}+\delta_{k}\right) \quad \forall i \\
& Q_{i}=Q_{g i}-Q_{d i(t)}=-\sum_{k=1}^{\mathrm{nb}}\left|V_{i}\right|\left|V_{k}\right|\left|Y_{i k}\right| \sin \left(\theta_{i k}-\delta_{i}+\delta_{k}\right) \quad \forall i
\end{aligned}
$$


Similarly, for the OUPFC incident buses, the real and reactive power balance equations can be written as

$$
\begin{aligned}
P_{i} & =P_{g i}-\left(P_{d i(t)}+P_{i n j, i}\right) \\
& =\sum_{k=1}^{\mathrm{nb}}\left|V_{i}\right|\left|V_{k} \| Y_{i k}\right| \cos \left(\theta_{i k}-\delta_{i}+\delta_{k}\right) \\
Q_{i} & =Q_{g i}-\left(Q_{d i(t)}+Q_{i n j, i}\right) \\
& =-\sum_{k=1}^{\mathrm{nb}}\left|V_{i}\right|\left|V_{k}\right|\left|Y_{i k}\right| \sin \left(\theta_{i k}-\delta_{i}+\delta_{k}\right)
\end{aligned}
$$

where $P_{i n j, i}$ and $Q_{i n j, i}$ are the real and reactive power injections by OUPFC as given in (1)-(4).

The inequality constraints mainly real and reactive power generations at CE sources, bus voltages, load angles, tap-changer settings, shunt VAr injections and line flow limits are considered as variables in the optimization.

$$
\begin{aligned}
& P_{g i}^{\min } \leq P_{g i} \leq P_{g i}^{\max } \quad i=1,2, \ldots, n \mathrm{CE} \\
& Q_{g i}^{\min } \leq Q_{g i} \leq Q_{g i}^{\max } \quad i=1,2, \ldots, n \mathrm{CE} \\
& \left|V_{i}^{\min }\right| \leq\left|V_{i}\right| \leq\left|V_{i}^{\max }\right| \ldots \quad i=1,2, \ldots, \mathrm{nb} \\
& \delta_{i}^{\min } \leq \delta_{i} \leq \delta_{i}^{\max } \quad i=1,2, \ldots, E \\
& a_{i}^{\min } \leq a_{i} \leq a_{i}^{\max } \quad i=1,2, \ldots, \mathrm{ntcl} \\
& Q_{c, i n j, i}^{\min } \leq Q_{c, i n j, i} \leq Q_{c, i n j, i}^{\max } \quad i=1,2, \ldots, \mathrm{nvcb} \\
& \left|S_{l}\right| \leq\left|S_{l}^{\max }\right| \quad l=1,2, \ldots, \mathrm{nl}
\end{aligned}
$$

\section{Cuckoo search optimization}

This section presents the optimization procedure for scheduling of CE sources, OUPFC and system parameters under different ambient temperature conditions by sing basic cuckoo search algorithm (CSA) and its proposed improved version.

\section{Overview of cuckoo search algorithm}

Cuckoo search algorithm (CSA) is one of the recent nature-inspired algorithms introduced by Yang in 2009 which inspired by brood reproductive strategy of cuckoo birds to increase their population, and it is more effective than other same family algorithms such as bat-inspired algorithm (BIA), differential evolution (DE), simulated annealing 
(SA), particle swarm optimization (PSO) and artificial bee colony (ABC) algorithms $[55,54]$. In fact, these algorithms are special cases of CSA and hence, CSA can outperform than these algorithms. The major difference between CSA to other similar algorithms is the balance between local random walk to global random walk by its switching parameter and hence effective in terms of convergence speed to reach global optima. The switching parameter pa $\epsilon[0,1]$ used to control the balance between local and global random walk and are related mathematically as defined in Eq. (33).

$$
\begin{aligned}
& v_{i}^{t+1}=v_{i}^{t}+\alpha s H\left(P_{a}-\varepsilon\right) \otimes\left(v_{j}^{t}-v_{k}^{t}\right) \\
& v_{i}^{t+1}=v_{i}^{t}+\alpha L(s, \lambda)
\end{aligned}
$$

where $v_{i}^{t}$ and $v_{k}^{t}$ are the current position selected by random permutation; $\alpha$ is positive step size scaling factor; $\mathrm{s}$ is step size; $\mathrm{H}$ is heavy-side function; $\mathrm{Pa}$ is switching parameter between local and global random walk; $\varepsilon$ is random number from uniform distribution; $\otimes$ is entry-wise product of two vectors; $L(s, \lambda)$ is Lévy distribution used to define the step size of random walk.

Lévy flights essentially provide a random walk while their random steps are drawn from a Lévy distribution for large steps. One of the effective methodologies to generate step size is using Mantegnas equations using gamma distribution function, described by;

$$
\begin{aligned}
& \lambda=\left\{\left|\left[\Gamma(1+\beta) \cdot \sin \left(\frac{\pi \beta}{2}\right)\right] /\left[\Gamma\left(\frac{1+\beta}{2}\right) \cdot \beta \cdot 2^{\left(\frac{\beta-1}{2}\right)}\right]\right|\right\}^{1 / \beta} \\
& \beta=\frac{3}{2} ; \quad u=\operatorname{rand}() \cdot \alpha ; \quad S=\frac{u}{|v|^{\frac{1}{\beta}}}
\end{aligned}
$$

where $\Gamma()$ is the gamma distribution function.

\section{Adaptive cuckoo search algorithm}

Precisely, the improvements for CSA toward better efficiency have been addressed by various researcher using different probability distributions for defining the step size of random walk and dynamically adjustment for switching parameter between local and global random walks. In [57], Gauss distribution-based CSA has proposed and results have shown the Gauss-CS outperformed than originally Levy-CSA in terms of higher convergence rate with reduced average generation. In [58], Gaussian and Cauchy distributions have been proposed and proved their superiority than Levy-CSA by applying to the web documents clustering problem. Similarly, Cauchy distribution-based CSA also in [59] and has applied for solving the economic emission load dispatch problem with multiple fuels options, but the results have shown Levy-CSA is better than other Gaussian-CSA and Cauchy-CSA by having lesser computational time. In [60, 61], Gamma distribution-based CSA has been proposed and proved the Gamma-CSA superiority than Levy-CSA in terms of accuracy and average time. On other side, lineally decreasing switching parameter instead of constant switching parameter in original CSA in [62] and sorting function instead of permutation [63] have been proposed for better efficiency. In 
addition, the reader can found some other significant literature on CSA improvements in [64].

Instead of constant switching parameter, a dynamically increasing switching parameter in a power of three is adopted in the proposed ACSA for adjusting the random walk between local optimal and global optima [47]. Mathematically,

$$
p_{a}^{(k)}=p_{a, \max } \times\left(\frac{k}{k_{\max }}\right)^{3}
$$

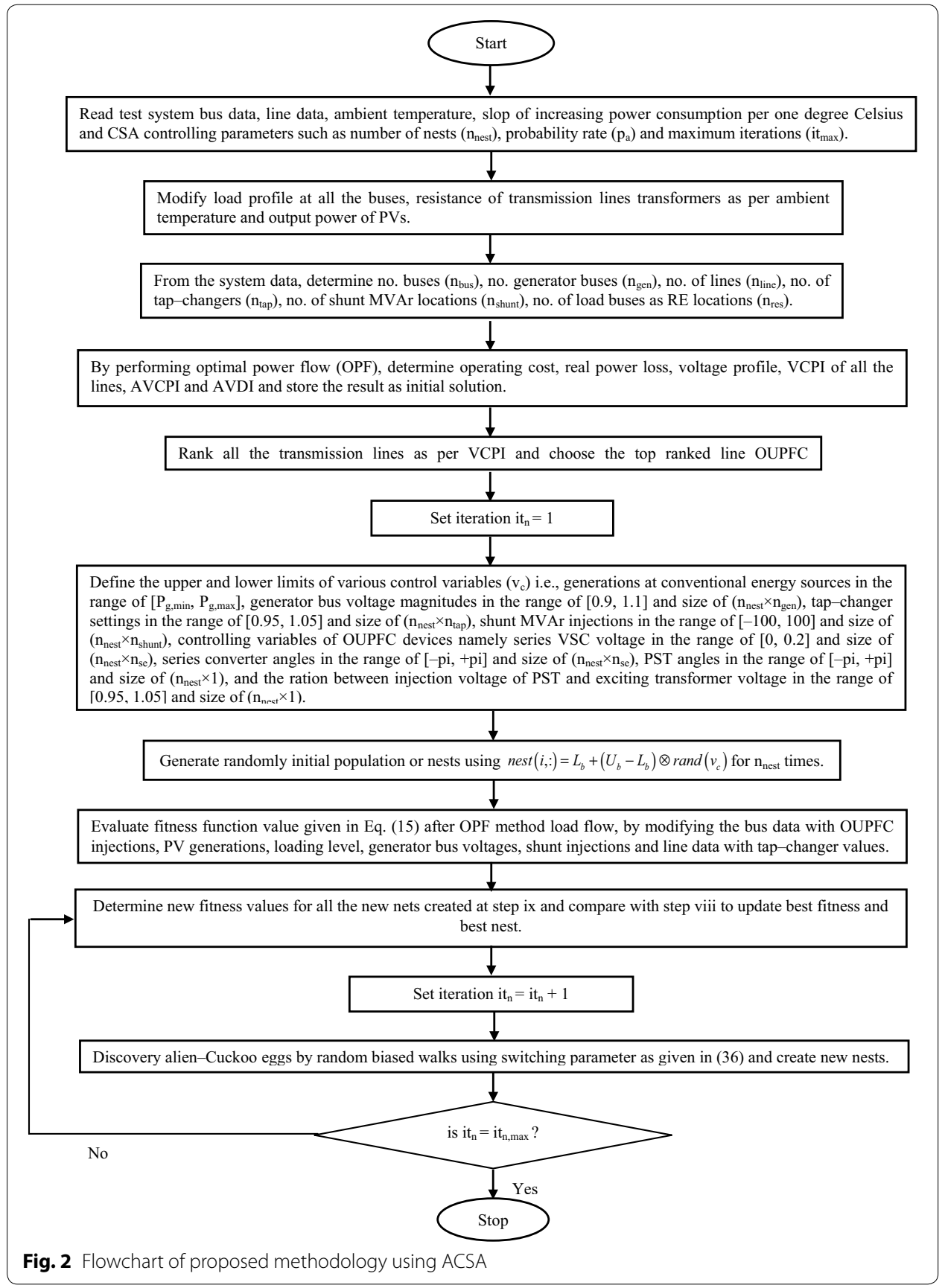




\section{Solution approach using CSA}

In this section, the control variable in the multi-objective problem and the overall procedure for solving the proposed fitness function is described here.

Vector of control variables This paper is aimed to minimize the voltage deviation w.r.t. reference voltage, real power loss and voltage collapse point indicator by considering variations in RE generation and loading conditions with OUPFC optimal controls. Here, the vector of control variables consists of generation at conventional energy sources, generator bus voltage magnitudes, tap-changer settings, shunt MVAr injection and controlling variables of OUPFC device.

Fitness function In each iteration, the system bus data and line data are updated with new population comprises generator bus voltage magnitudes, tap-changer ratios, shunt MVAr injections, controlling variables of OUPFC device (UPFC voltage source magnitude and its angle as well as PST voltage regulation and its angle) and correspondingly power injections at their incident buses. By having NR power flow solution, total real power loss, average VCPI and average voltage deviation index are computed to update the overall objective function expressed in Eq. (16). The solution that minimizes the overall objective function is considered the best solution.

The overall procedure of the proposed ACSA approach for solving OPF problem is given as flowchart in Fig. 2.

\section{Results and discussion}

The effectiveness of the proposed ACSA approach for solving the OPF problem including OUPFC is illustrated using standard IEEE 14, 30 and 118-bus systems. The bus data, line data and cost coefficients of generator buses for all the test systems are taken from [65]. The simulations are carried out in MATLAB 7.8 environment installed in Pentium 4 (Core 2 Quad) $2.83 \mathrm{GHz}$ personal computer of 4 GB RAM.

The simulations are performed for 5 different assumed weather and load growth scenarios: $(1 \mathrm{Ta}$ (ambient temperature $)=250 \mathrm{C}$, Gt $($ global irradiance $)=1000 \mathrm{~W} / \mathrm{m}^{2}, \mathrm{~m}$ (slop of the load growth curve) $=0$, (2) $\mathrm{Ta}=30^{\circ} \mathrm{C}, \mathrm{Gt}=875 \mathrm{~W} / \mathrm{m}^{2}, m=0.025$, (3) $\mathrm{Ta}=34$ ${ }^{\circ} \mathrm{C}, \mathrm{Gt}=900 \mathrm{~W} / \mathrm{m}^{2}, \mathrm{~m}=0.05,(4) \mathrm{Ta}=38{ }^{\circ} \mathrm{C}, \mathrm{Gt}=925 \mathrm{~W} / \mathrm{m}^{2}, m=0.075$ and (5) $\mathrm{Ta}=42$ ${ }^{\circ} \mathrm{C}, \mathrm{Gt}=950 \mathrm{~W} / \mathrm{m}^{2}, \mathrm{~m}=0.1$. Each scenario is repeated for 2 cases: (a) without considering PV systems and OUPFC in the network and (b) considering PV systems and OUPFC in the network.

In general, the PV systems are not dispatchable and hence their minimum and maximum limits are considered equal to the actual generation at the specified weather conditions and not considered as controlling variable in the OPF problem. The MVA rating of PV inverter is assumed as equal to the installed plant capacity of PV system and their operating power factor is assumed commonly as 0.95 leading, and hence, they can also able to support reactive power as modeled in Eq. (13).

In all the case studies, it is considered as reference temperature $\left(T_{\text {ref }}\right)=25^{\circ} \mathrm{C}$, temperature constant $\left(T_{\mathrm{c}}\right)=228.1{ }^{\circ} \mathrm{C}$ for hard-drawn aluminum conductors and $225^{\circ} \mathrm{C}$ for aluminum transformer $[42,54]$. The operating constraints are considered as mentioned in section Problem formulation, step 6. Also, the parameters for ACSA are considered as follows: number of nests $\left(n_{\text {nest }}\right)=25$, probability rate $\left(p_{\mathrm{a}}\right)=0.25$, and maximum iterations $\left(\mathrm{it}_{\max }\right)=50$. 


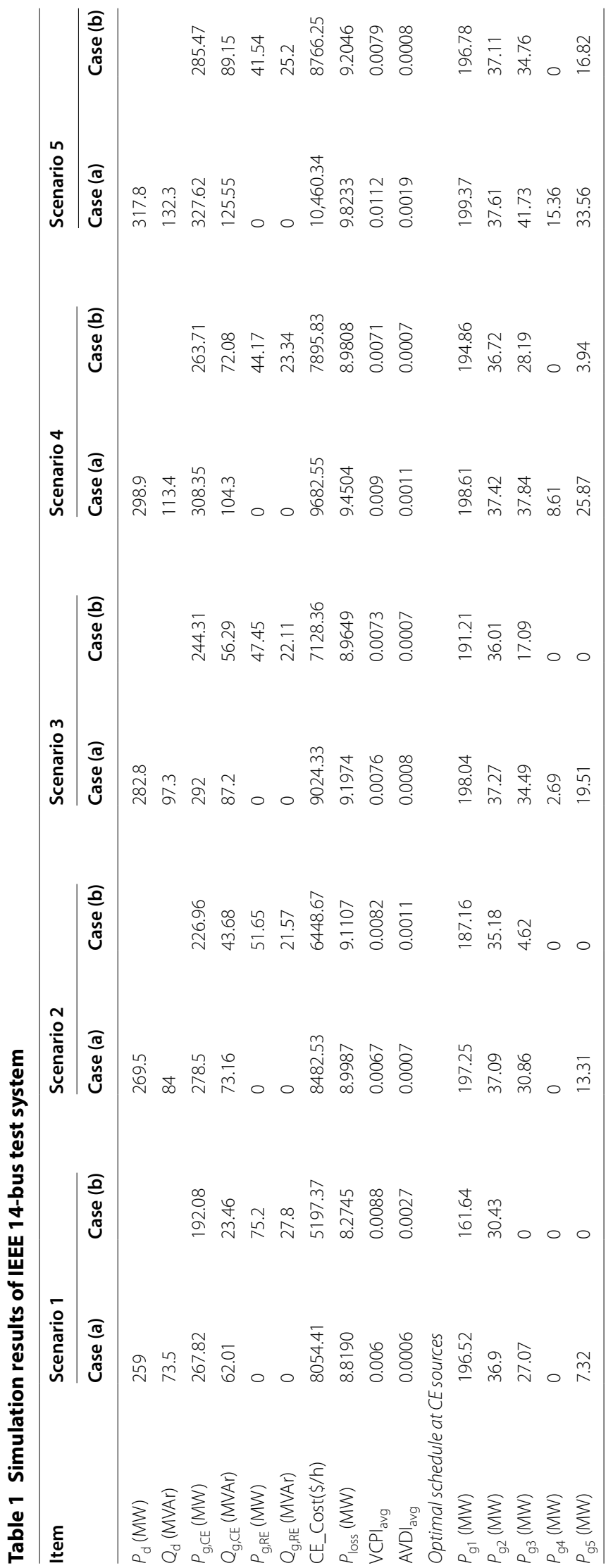




\section{IEEE 14-bus system}

This test system consists of 5 generator buses, 9 load buses in which bus- 9 is having shunt VAr injection. The buses are interconnected by 20 transmission lines, in which 3 are having tap-changing transformers. The line MVA ratings are given in Appendix. It has totally $259 \mathrm{MW}$ real power and 73.5 MVAr reactive power loads, respectively. It is assumed that the existing all generator buses in the standard test system as CE sources.

Scenario 1 Since scenario (1) is similar to the normal test system without PV sources and OUPFC, the loading on the system remains equal to $259 \mathrm{MW}$ real and 73.5 MVAr reactive loads, respectively. In case (a), the test system is assumed for weather impact only on system loading conditions and transmission system parameters. The optimal schedule of CE sources and different objective function values are given in Table 1 as scenario (1) under case (a). The operating cost $\left(F_{1}\right)$ for optimal schedule is equal to $8054.41 \$ / \mathrm{h}$. For this schedule, the system has $8.819 \mathrm{MW}$ real power losses $\left(F_{2}\right)$, average voltage stability index $\left(F_{3}\right)$ is 0.006 and average voltage deviation index $\left(F_{4}\right)$ is equal to 0.0006 .

In order to simulate case (b), buses-10, 11 and 12 are treated as solar PV generation sources with $25 \mathrm{MW}$ installed capacity of each. TP250 series of TATA Power Solar module [48] is considered for all the PV systems, and its specifications are as follows: $I_{\mathrm{sc}}=8.71 \mathrm{~A} ; V_{\text {oc }}=37.3 \mathrm{~V} ; V_{\mathrm{m}}=30.2 \mathrm{~V} ; I_{\mathrm{m}}=8.3 \mathrm{~A}$.

Also, the following strategy is followed for identifying OUPFC location. By excluding the transmission lines which are incident to generator buses, shunt VAr injection buses and the lines having tap-changers, the remaining lines are ranked based on their VCPI values. Among all, the line connected between bus-13 and bus-14 is stood in first place by having highest value of VCPI $=0.0099$ and considered as optimal location for the integration of OUPFC.

In case (b), the actual loading condition is still remaining same due to load growth $\mathrm{m}=0$, but the CE sources are optimally scheduled for only effective loading (of 192.08 MW and 23.46 MVAr real and reactive power, respectively), which can obtain by reducing the total PV generation of 75.2 MW and 27.8 MVAr real and reactive powers, respectively. The corresponding operating cost $\left(F_{1}\right)$ at CE sources is reduced to 5197.37 $\$ / \mathrm{h}$ from 8054.41 \$ $/ \mathrm{h}$. By having this optimal schedule at CE sources, PV generations and OUPFC controls in the network, the real power losses $\left(F_{2}\right)$ have reduced to 8.2745 from 8.819 MW. But notably, the average voltage stability index $\left(F_{3}\right)$ is increased to 0.0088 from 0.006 and average voltage deviation index $\left(F_{4}\right)$ is increased to 0.0027 from 0.006 .

Scenario 2 In scenario 2, the weather conditions are considered little bit higher than scenario 1 . Due to increased slop of load growth, the real power loading conditions are increased to $269.5 \mathrm{MW}$ from $259 \mathrm{MW}$. As compared to case (a) in scenario 1, the operating cost is increased $8482.53 \$ / \mathrm{h}$ from $8054.41 \$ / \mathrm{h}$, losses are increased to $8.9987 \mathrm{MW}$ from $8.819 \mathrm{MW}$, stability index increased to 0.0067 from 0.006 and voltage deviation index is increased to 0.0007 from 0.0006 , respectively. This operating condition is clearly indicating the negative impact on system operating condition due to rise in ambient temperature and load growth.

In case (b), the PV generation is also decreased to $51.65 \mathrm{MW}$ from $75.2 \mathrm{MW}$ and 21.57 MVAr from 27.8 MVAr due to rise in ambient temperature. The optimal schedule at CE sources and correspondingly objective functions with PV sources and OUPFC controls 


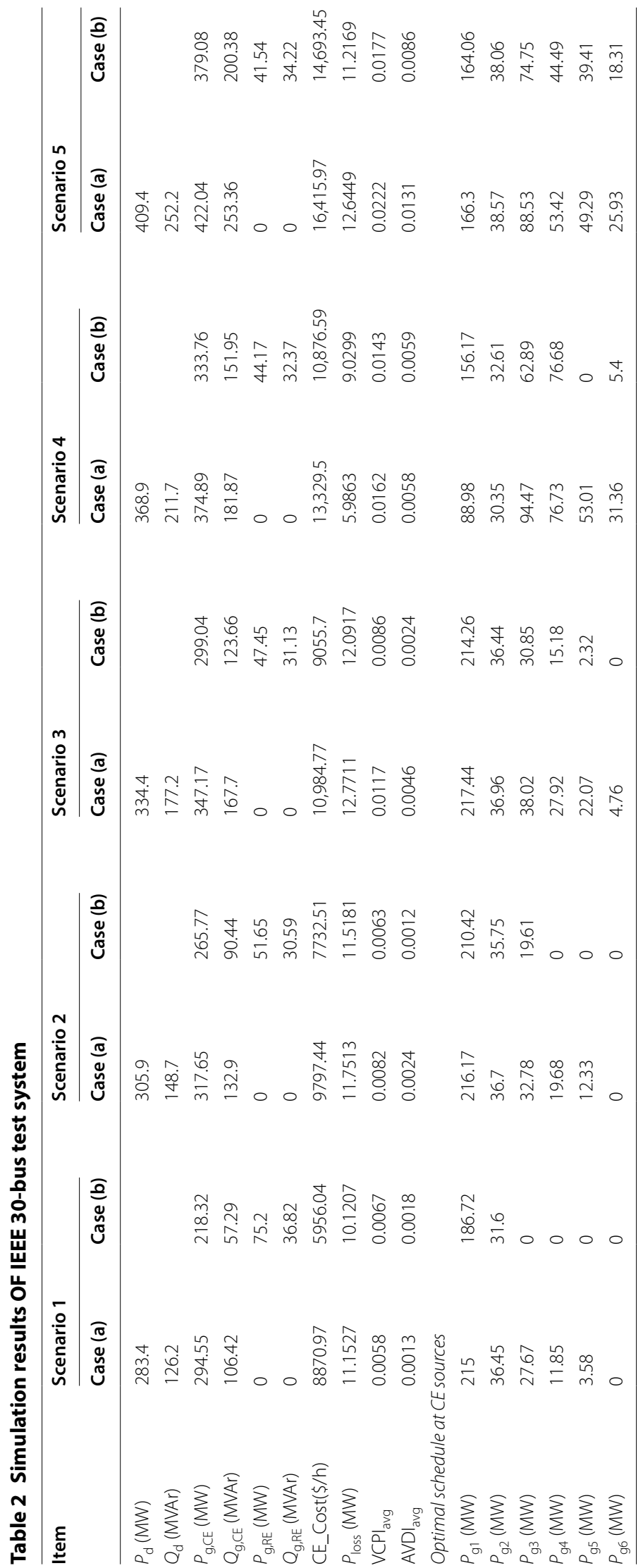


in the network are given in Table 2 as scenario 2 under case (b). It is observed that the operating cost of CE is decreased to $6448.67 \$ / \mathrm{h}$ from $8482.53 \$ / \mathrm{h}$, whereas losses, stability index and voltage deviation indexes are increased considerably.

Scenario 3 Under this scenario, the test system loading is increased to 282.8 MW. The generation is increased to 292.00 at $\mathrm{CE}$ sources including losses. Correspondingly, the system has $F_{1}=9024.33 \$ / \mathrm{h}, F_{2}=9.1974 \mathrm{MW}, F_{3}=0.0076$ and $F_{4}=0.0008$. In case (b), the test system has OUPFC controls and PV generation equal to $47.45 \mathrm{MW}$ and 22.11 MVAr; consequently, the CE sources are scheduled optimally for $244.31 \mathrm{MW}$. For this optimal schedule, the system has an operating cost $\left(F_{1}\right)=7128.36 \$ / \mathrm{h}$, losses $\left(F_{2}\right)=8.8649 \mathrm{MW}$, stability index $\left(F_{3}\right)=0.0073$ and voltage deviation index $\left(F_{4}\right)=0.0007$. The optimal schedule at CE sources and correspondingly objective functions with PV sources and OUPFC controls in the network are given in Table 2 as scenario 3 under case (b).

Scenario 4: Under this scenario, the test system loading is increased to 298.9 MW. The generation is increased to $308.35 \mathrm{MW}$ at CE sources including losses. Correspondingly, the system has $F_{1}=9682.55 \$ / \mathrm{h}, F_{2}=9.4504 \mathrm{MW}, F_{3}=0.009$ and $F_{4}=0.0011$. In case (b), the test system has OUPFC controls and PV generation equal to $44.17 \mathrm{MW}$ and 23.34 MVAr; consequently, the CE sources are scheduled optimally for $263.71 \mathrm{MW}$. For this optimal schedule, the system has an operating cost $\left(F_{1}\right)=7895.83 \$ / \mathrm{h}$, losses $\left(F_{2}\right)=8.9808 \mathrm{MW}$, stability index $\left(F_{3}\right)=0.0071$ and voltage deviation index $\left(F_{4}\right)=0.0007$. The optimal schedule at CE sources and correspondingly objective functions with PV sources and OUPFC controls in the network are given in Table 2 as scenario 4 under case (b).

Scenario 5 Under this scenario, the test system loading is increased to $317.8 \mathrm{MW}$. The generation is increased to $327.65 \mathrm{MW}$ at $\mathrm{CE}$ sources including losses. Correspondingly, the system has $F_{1}=10,460.34 \$ / \mathrm{h}, F_{2}=9.8233 \mathrm{MW}, F_{3}=0.0112$ and $F_{4}=0.0019$. In case (b), the test system has OUPFC controls and PV generation equal to 41.54 MW and 25.2 MVAr; consequently, the CE sources are scheduled optimally for 285.47 MW. For this optimal schedule, the system has an operating cost $\left(F_{1}\right)=8766.25 \$ / \mathrm{h}$, losses $\left(F_{2}\right)=9.2046 \mathrm{MW}$, stability index $\left(F_{3}\right)=0.0079$ and voltage deviation index $\left(F_{4}\right)=0.0008$. The optimal schedule at CE sources and correspondingly objective functions with PV sources and OUPFC controls in the network are given in Table 2 as scenario 5 under case (b).

\section{IEEE 30-bus system}

The test system has 6 generators buses (assumed as CE sources), 24 load buses of which 2 buses are having shunt MVAr injections and connected by 41 transmissions in which 4 lines are having tap0.00changers. It has totally 283.4 MW and 126.2 MVAr real and reactive power loads, respectively. In this test system, 3 locations namely buses 12, 17, and 21 are assumed as PV sources of $25 \mathrm{MW}$ capacity each. For the optimal location of OUPFC, the methodology explained in IEEE 14-bus system is followed here also. As per highest value of $\mathrm{VCPI}=0.0168$, line 38 connected between bus-27 and bus-30 is selected for OUPFC integration.

Scenario 1 Under this scenario, the test system loading remains equal to 283.4 MW and 126.2 MVAr. The total generation at CE sources is $294.55 \mathrm{MW}$ at CE sources 
including losses. Correspondingly, the system has $F_{1}=8870.97 \$ / \mathrm{h}, F_{2}=11.1527 \mathrm{MW}$, $F_{3}=0.0058$ and $F_{4}=0.0013$. In case (b), the test system has OUPFC controls and PV generation equal to 75.2 MW and 36.82 MVAr; consequently, the CE sources are scheduled optimally for $218.32 \mathrm{MW}$. For this optimal schedule, the system has an operating cost $\left(F_{1}\right)=5956.04 \$ / \mathrm{h}$, losses $\left(F_{2}\right)=10.1207 \mathrm{MW}$, stability index $\left(F_{3}\right)=0.0067$ and voltage deviation index $\left(F_{4}\right)=0.0018$. The optimal schedule at $C E$ sources and correspondingly objective functions with PV sources and OUPFC controls in the network are given in Table 2 as scenario 1 under case (b).

Scenario 2 Under this scenario, the test system loading is increased to 305.9 MW from 283.4 MW. The total generation at CE sources is $317.65 \mathrm{MW}$ at CE sources including losses. Correspondingly, the system has $F_{1}=9797.44 \$ / \mathrm{h}, F_{2}=11.7513 \mathrm{MW}, F_{3}=0.0082$ and $F_{4}=0.0024$. In case (b), the test system has OUPFC controls and PV generation equal to 51.65 MW and 30.59 MVAr; consequently, the CE sources are scheduled optimally for $265.77 \mathrm{MW}$. For this optimal schedule, the system has an operating cost $\left(F_{1}\right)=7732.51 \$ / \mathrm{h}$, losses $\left(F_{2}\right)=11.5181 \mathrm{MW}$, stability index $\left(F_{3}\right)=0.0063$ and voltage deviation index $\left(F_{4}\right)=0.0012$. The optimal schedule at $\mathrm{CE}$ sources and correspondingly objective functions with PV sources and OUPFC controls in the network are given in Table 2 as scenario 2 under case (b).

Scenario 3 Under this scenario, the test system loading is increased to 334.4 MW from 283.4 MW. The total generation at CE sources is 347.17 MW at CE sources including losses. Correspondingly, the system has $F_{1}=10,984.77 \$ / \mathrm{h}, F_{2}=12.7711 \mathrm{MW}$, $F_{3}=0.0117$ and $F_{4}=0.0046$. In case (b), the test system has OUPFC controls and PV generation equal to $47.45 \mathrm{MW}$ and 31.13 MVAr; consequently, the CE sources are scheduled optimally for 299.04 MW. For this optimal schedule, the system has an operating cost $\left(F_{1}\right)=9055.7 \$ / \mathrm{h}$, losses $\left(F_{2}\right)=12.0917 \mathrm{MW}$, stability index $\left(F_{3}\right)=0.0086$ and voltage deviation index $\left(F_{4}\right)=0.0024$. The optimal schedule at CE sources and correspondingly objective functions with PV sources and OUPFC controls in the network are given in Table 2 as scenario 3 under case (b).

Scenario 4 Under this scenario, the test system loading is increased to 368.9 MW from 283.4 MW. The total generation at CE sources is $374.89 \mathrm{MW}$ at CE sources including losses. Correspondingly, the system has $F_{1}=13,329.5 \$ / \mathrm{h}, F_{2}=5.9863 \mathrm{MW}, F_{3}=0.0162$ and $F_{4}=0.0058$. In case (b), the test system has OUPFC controls and PV generation equal to $44.171 \mathrm{MW}$ and 32.37 MVAr; consequently, the CE sources are scheduled optimally for $333.76 \mathrm{MW}$. For this optimal schedule, the system has an operating cost $\left(F_{1}\right)=10,876.59 \$ / \mathrm{h}$, losses $\left(F_{2}\right)=9.0299 \mathrm{MW}$, stability index $\left(F_{3}\right)=0.0143$ and voltage deviation index $\left(F_{4}\right)=0.0059$. The optimal schedule at $\mathrm{CE}$ sources and correspondingly objective functions with PV sources and OUPFC controls in the network are given in Table 2 as scenario 4 under case (b).

Scenario 5 Under this scenario, the test system loading is increased to 409.4 MW from 283.4 MW. The total generation at CE sources is $422.04 \mathrm{MW}$ at CE sources including losses. Correspondingly, the system has $F_{1}=16,415.97 \$ / \mathrm{h}, F_{2}=12.6449 \mathrm{MW}$, $F_{3}=0.0222$ and $F_{4}=0.0131$. In case (b), the test system has OUPFC controls and PV generation equal to 41.54 $\mathrm{MW}$ and 34.22 MVAr; consequently, the CE sources are scheduled optimally for $379.08 \mathrm{MW}$. For this optimal schedule, the system has an operating cost $\left(F_{1}\right)=14,693.45 \$ / \mathrm{h}$, losses $\left(F_{2}\right)=11.2169 \mathrm{MW}$, stability index $\left(F_{3}\right)=0.0177$ 


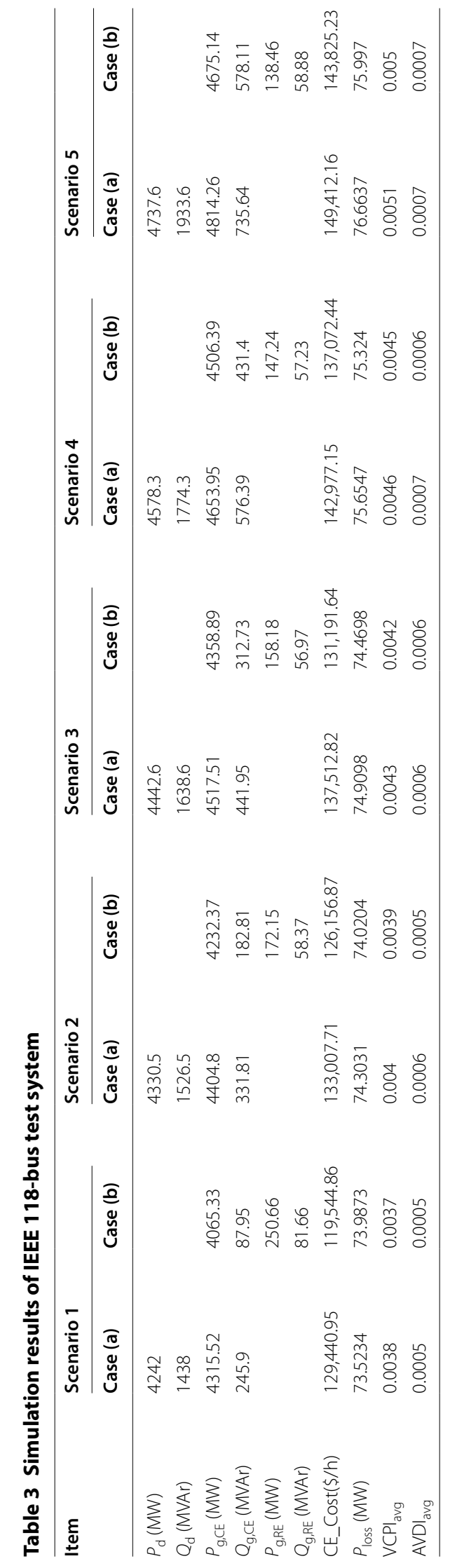




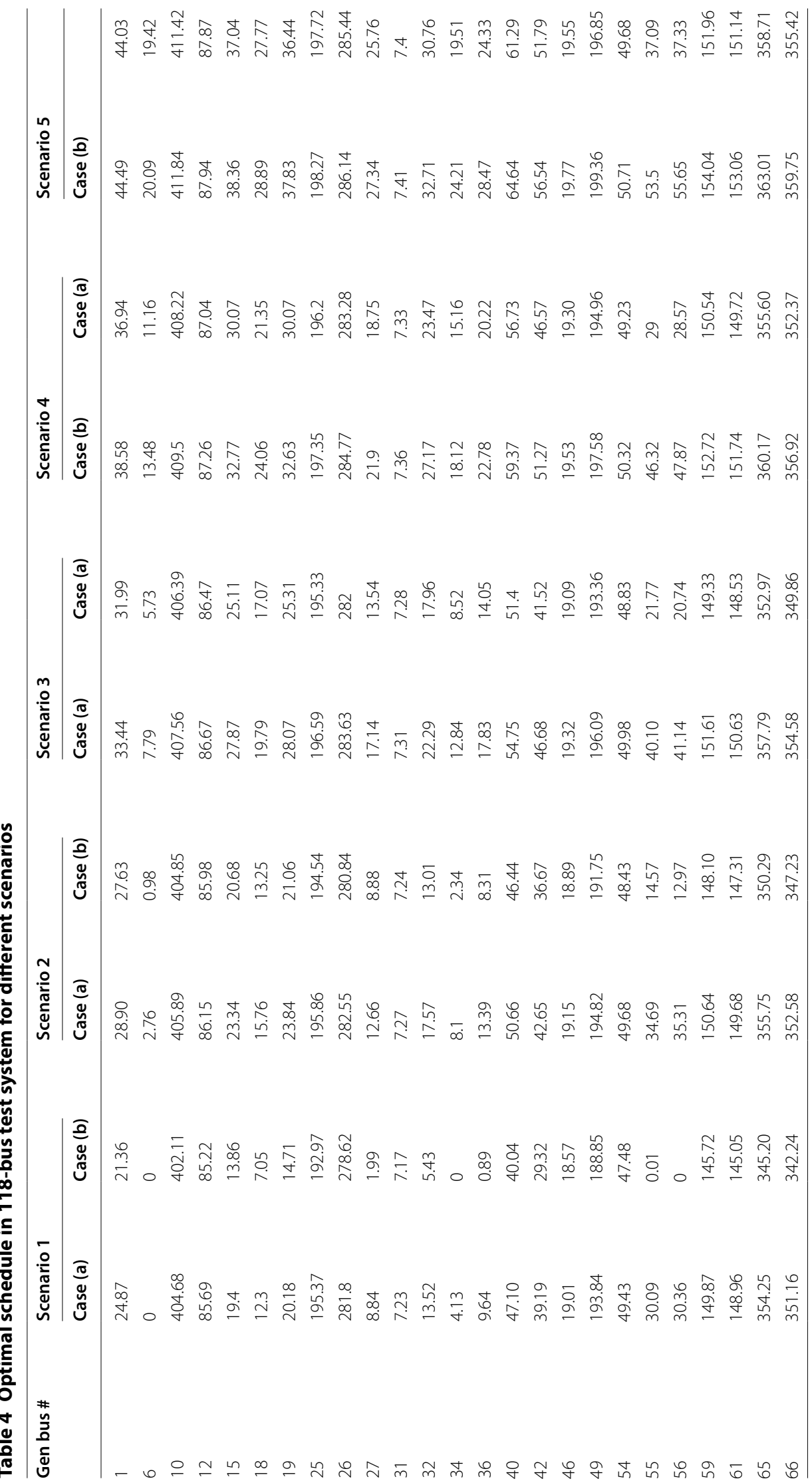




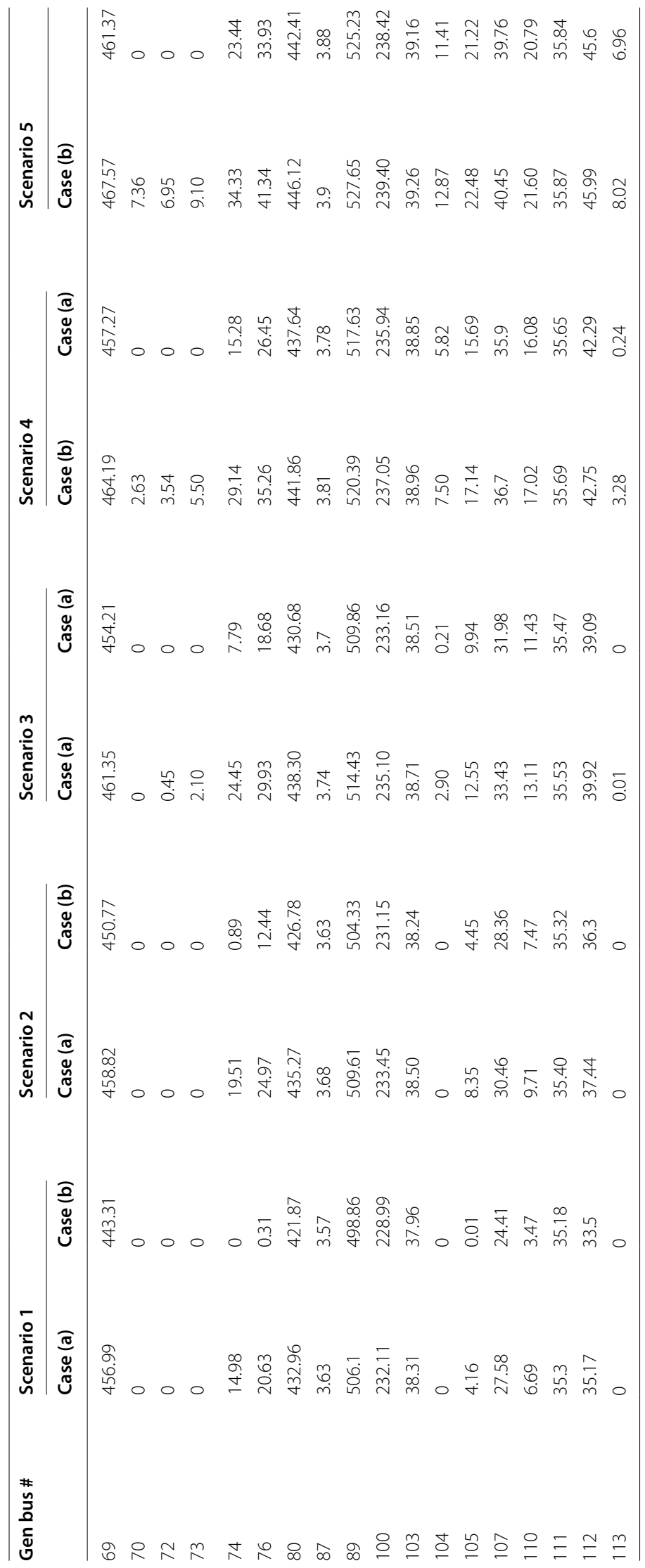


and voltage deviation index $\left(F_{4}\right)=0.0086$. The optimal schedule at CE sources and correspondingly objective functions with PV sources and OUPFC controls in the network are given in Table 2 as scenario 5 under case (b).

\section{IEEE 118-bus system}

This test system consists of 54 generator buses and 64 load buses in which 10 buses are with shunt VAr injections and 2 buses are with shunt reactors. All the buses are interconnected by 186 interconnected transmission lines, in which 9 are with tap-changing transformers. It has totally $4242 \mathrm{MW}$ real and $1438 \mathrm{MVAr}$ reactive loads, respectively.

It is assumed that the existing all generator buses in the system as CE sources and 5 load buses, i.e., 53, 54, 70, 71 and 78 are installed with $50 \mathrm{MW}$ solar PV systems. According to VCPI values, lines are ranked and line-54 with 0.0182 (connected between bus- 30 to bus-38) and line-126 with 0.0112 (connected between bus-68 to bus-81) are top-ranked and chosen for two OUPFC devices integration simultaneously. In this test system, the MVA limits for transmission lines are not considered in the optimization problem. The test system loading details under different scenarios and correspondingly obtained objective functions are given in Table 3. Also, the optimal generation schedules of all CE sources are given in Table 4. There are certain generators (i.e., 4, 8, 24, 62, 77, $85,90,91,92,99$ and 116) which are not picked up generation under any scenario and hence not listed in Table 4.

Scenario 1 Under this scenario, the test system loading remains equal to $4242 \mathrm{MW}$ and 1438 MVAr. The total generation at CE sources is $4315.5234 \mathrm{MW}$ at CE sources including losses. Correspondingly, the system has $F_{1}=129,440.95 \$ / \mathrm{h}, F_{2}=73.5234 \mathrm{MW}$, $F_{3}=0.0038$ and $F_{4}=0.0005$. In case (b), the test system has 2 OUPFC controls and PV generation at 5 locations equal to $250.66 \mathrm{MW}$ and $81.66 \mathrm{MVAr}$; consequently, the $\mathrm{CE}$ sources are scheduled optimally for $4065.33 \mathrm{MW}$. For this optimal schedule, the system has an operating cost $\left(F_{1}\right)=119,544.86 \$ / \mathrm{h}$, losses $\left(F_{2}\right)=73.9873 \mathrm{MW}$, stability index $\left(F_{3}\right)=0.004$ and voltage deviation index $\left(F_{4}\right)=0.0006$. The optimal schedule at CE sources and correspondingly objective functions with PV sources and OUPFC controls in the network are given in Table 3 as scenario 1 under case (b).

Scenario 2 Under this scenario, the test system loading is increased to $4330.5 \mathrm{MW}$ from $4242 \mathrm{MW}$. The total generation at CE sources is $4404.8 \mathrm{MW}$ at CE sources including losses. Correspondingly, the system has $F_{1}=133,007.71 \$ / \mathrm{h}, F_{2}=74.3031 \mathrm{MW}$, $F_{3}=0.004$ and $F_{4}=0.0006$. In case (b), the test system has OUPFC controls and PV generation equal to $172.15 \mathrm{MW}$ and 58.37 MVAr; consequently, the CE sources are scheduled optimally for $4232.37 \mathrm{MW}$. For this optimal schedule, the system has an operating cost $\left(F_{1}\right)=126,156.87 \$ / \mathrm{h}$, losses $\left(F_{2}\right)=74.0204 \mathrm{MW}$, stability index $\left(F_{3}\right)=0.0039$ and voltage deviation index $\left(F_{4}\right)=0.0005$. The optimal schedule at $\mathrm{CE}$ sources and correspondingly objective functions with PV sources and OUPFC controls in the network are given in Table 3 as scenario 2 under case (b).

Scenario 3 Under this scenario, the test system loading is increased to $4442.6 \mathrm{MW}$ from $4242 \mathrm{MW}$. The total generation at CE sources is $4517.51 \mathrm{MW}$ at CE sources including losses. Correspondingly, the system has $F_{1}=137,512.82 \$ / \mathrm{h}, F_{2}=74.9098 \mathrm{MW}$, $F_{3}=0.0043$ and $F_{4}=0.0006$. In case (b), the test system has OUPFC controls and PV 
Table 5 Comparison of different algorithms for scenario 5 (Case A: without RES) in 118-bus test system

\begin{tabular}{|c|c|c|c|c|c|c|c|c|}
\hline \multirow[t]{2}{*}{ Item } & \multicolumn{8}{|l|}{ Algorithm } \\
\hline & ACSA & CSA & PSO & CSO & FPA & GOA & WOA & ALO \\
\hline$P_{\mathrm{g}, \mathrm{CE}}(\mathrm{MW})$ & 4814.26 & 4815.33 & 4816.42 & 4817.54 & 4818.68 & 4815.43 & 4816.28 & 4818.61 \\
\hline $\begin{array}{l}Q_{g, C E} \\
\text { (MVAr) }\end{array}$ & 735.64 & 771.7 & 807.62 & 843.43 & 879.1 & 793.1 & 802.43 & 842.98 \\
\hline $\mathrm{CE}_{-} \operatorname{Cost}(\$ / h)$ & $149,412.94$ & $149,416.68$ & $149,421.01$ & $149,417.58$ & $149,419.38$ & $149,413.62$ & $149,414.72$ & $149,414.23$ \\
\hline$P_{\text {loss }}(\mathrm{MW})$ & 77.8337 & 78.2312 & 78.8231 & 78.9396 & 79.0818 & 78.2741 & 78.3292 & 80.3361 \\
\hline $\mathrm{VCPl}_{\mathrm{avg}}$ & 0.0051 & 0.0052 & 0.0053 & 0.0054 & 0.0055 & 0.0052 & 0.0054 & 0.0054 \\
\hline $\mathrm{AVDI}_{\text {avg }}$ & 0.0007 & 0.0007 & 0.0007 & 0.0007 & 0.0007 & 0.0007 & 0.0007 & 0.0007 \\
\hline OF & $149,490.78$ & $149,494.92$ & $149,499.84$ & $149,496.53$ & $149,498.47$ & $149,491.9$ & $149,493.06$ & $149,494.57$ \\
\hline Time (s) & 1.73 & 1.92 & 2.02 & 1.95 & 1.88 & 1.82 & 1.93 & 2.04 \\
\hline
\end{tabular}

generation equal to 158.18 MW and 56.97 MVAr; consequently, the CE sources are scheduled optimally for $4358.89 \mathrm{MW}$. For this optimal schedule, the system has an operating cost $\left(F_{1}\right)=131,191.64 \$ / \mathrm{h}$, losses $\left(F_{2}\right)=74.4698 \mathrm{MW}$, stability index $\left(F_{3}\right)=0.0042$ and voltage deviation index $\left(F_{4}\right)=0.0006$. The optimal schedule at CE sources and correspondingly objective functions with PV sources and OUPFC controls in the network are given in Table 3 as scenario 3 under case (b).

Scenario 4 Under this scenario, the test system loading is increased to $4578.3 \mathrm{MW}$ from $4242 \mathrm{MW}$. The total generation at CE sources is $4653.95 \mathrm{MW}$ at CE sources including losses. Correspondingly, the system has $F_{1}=142,977.15 \$ / \mathrm{h}, F_{2}=75.6547 \mathrm{MW}$, $F_{3}=0.0046$ and $F_{4}=0.0007$. In case (b), the test system has OUPFC controls and PV generation equal to 147.24 MW and 57.23 MVAr; consequently, the CE sources are scheduled optimally for $4506.39 \mathrm{MW}$. For this optimal schedule, the system has an operating cost $\left(F_{1}\right)=137,072.44 \$ / \mathrm{h}$, losses $\left(F_{2}\right)=75.324 \mathrm{MW}$, stability index $\left(F_{3}\right)=0.0045$ and voltage deviation index $\left(F_{4}\right)=0.0006$. The optimal schedule at CE sources and correspondingly objective functions with PV sources and OUPFC controls in the network are given in Table 3 as scenario 4 under case (b).

Scenario 5 Under this scenario, the test system loading is increased to $4737.6 \mathrm{MW}$ from $4242 \mathrm{MW}$. The total generation at CE sources is $4814.26 \mathrm{MW}$ at CE sources including losses. Correspondingly, the system has $F_{1}=149,412.16 \$ / \mathrm{h}, F_{2}=76.6637 \mathrm{MW}$, $F_{3}=0.0051$ and $F_{4}=0.0007$. In case (b), the test system has OUPFC controls and PV generation equal to $138.46 \mathrm{MW}$ and 58.88 MVAr; consequently, the CE sources are scheduled optimally for 4675.14 MW. For this optimal schedule, the system has an operating cost $\left(F_{1}\right)=143,825.23 \$ / \mathrm{h}$, losses $\left(F_{2}\right)=75.997 \mathrm{MW}$, stability index $\left(F_{3}\right)=0.005$ and voltage deviation index $\left(F_{4}\right)=0.007$. The optimal schedule at CE sources and correspondingly objective functions with PV sources and OUPFC controls in the network are given in Table 3 as scenario 5 under case (b).

Case (a) and (b) of scenario 5 are simulated with basic CSA, flower pollination algorithm (FPA), chicken swarm optimization (CSO) and particle swarm optimization (PSO), grasshopper optimization algorithm (GOA), whale optimization algorithm (WOA) and ant lion optimization (ALO) algorithms and the results given in Table 5 for case (a) and in Table 6 for case (b), respectively. By observing the results, ACSA is 
Table 6 Comparison of different algorithms for scenario 5 (Case B: with RES) in 118-bus test system

\begin{tabular}{|c|c|c|c|c|c|c|c|c|}
\hline \multirow[t]{2}{*}{ Item } & \multicolumn{8}{|l|}{ Algorithms } \\
\hline & ACSA & CSA & PSO & CSO & FPA & GOA & WOA & ALO \\
\hline$P_{\mathrm{g}, \mathrm{CE}}(\mathrm{MW})$ & 4675.1 & 4676.25 & 4677.25 & 4678.45 & 4679.21 & 4675.56 & 4676.84 & 4676.33 \\
\hline$Q_{g, C E}(M V A r)$ & 570.94 & 625.77 & 667.58 & 705.48 & 757.12 & 588.49 & 659.29 & 739.72 \\
\hline$P_{\mathrm{g}, \mathrm{RE}}(\mathrm{MW})$ & 138.46 & 138.46 & 138.46 & 138.46 & 138.46 & 138.46 & 138.46 & 138.46 \\
\hline$Q_{g, R E}(M V A r)$ & 58.88 & 58.88 & 58.88 & 58.88 & 58.88 & 58.88 & 58.88 & 58.88 \\
\hline $\mathrm{CE}_{-} \operatorname{Cost}(\$ / \mathrm{h})$ & $143,828.77$ & $143,830.51$ & $1,430,833.74$ & $1,430,829.20$ & $1,430,831.16$ & $143,830.36$ & $143,829.20$ & $143,830.63$ \\
\hline$P_{\text {loss }}(\mathrm{MW})$ & 75.9561 & 77.1091 & 78.1138 & 79.3126 & 79.076 & 76.1561 & 76.2561 & 77.3223 \\
\hline $\mathrm{VCP}_{\text {avg }}$ & 0.005 & 0.0051 & 0.0052 & 0.0053 & 0.0054 & 0.0052 & 0.0054 & 0.0054 \\
\hline $\mathrm{AVDI}_{\mathrm{avg}}$ & 0.0007 & 0.0007 & 0.0007 & 0.0007 & 0.0007 & 0.0007 & 0.0007 & 0.0007 \\
\hline OF & $143,904.73$ & $143,907.62$ & $1,430,911.86$ & $1,430,908.52$ & $1,430,910.24$ & $143,906.52$ & $143,905.46$ & $143,907.96$ \\
\hline Time (s) & 1.03 & 2.14 & 1.9 & 1.14 & 1.91 & 1.56 & 1.88 & 1.72 \\
\hline
\end{tabular}

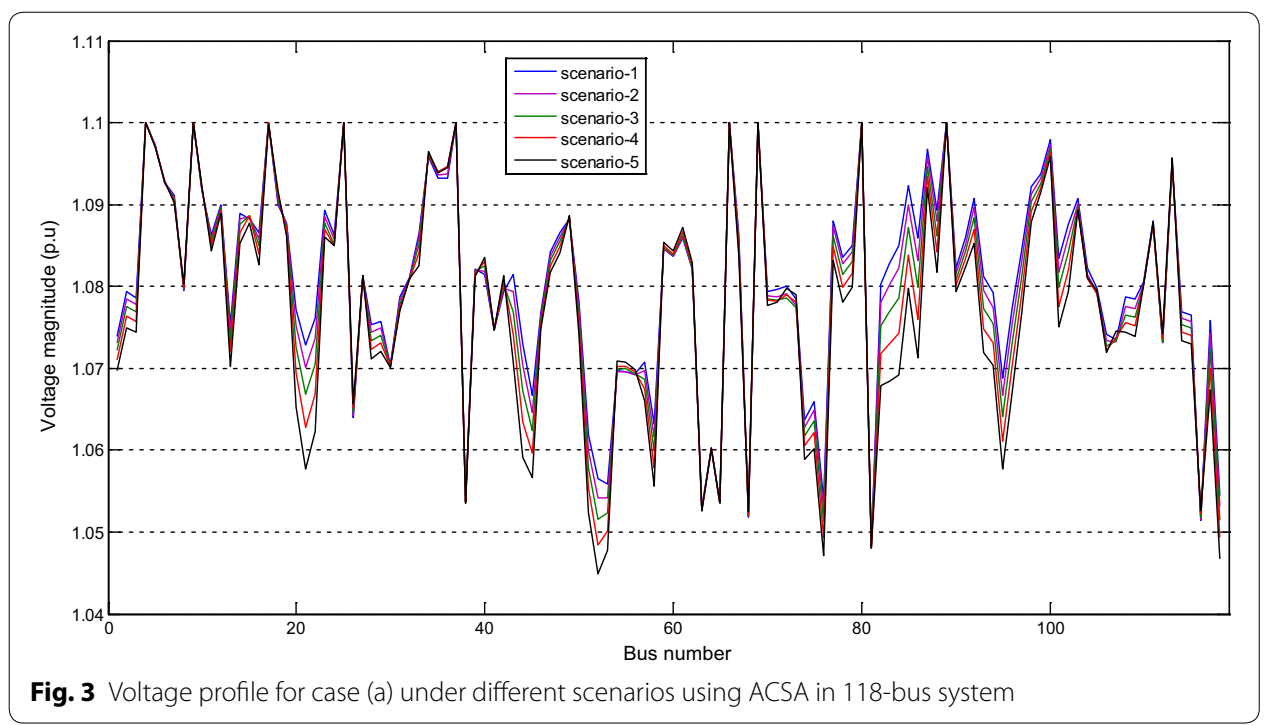

outperformed than CSA and PSO by providing the lowest objective function values. Due to space constraints, the voltage profiles obtained only with ACSA for case (a) and case (b) in all the scenarios are given in Fig. 3 and Fig. 4, respectively. From the results, the test system has minimum voltage in case (a) is 1.0448 p.u. (see Fig. 3) and in case (b), it is 1.0478 p.u. (see Fig. 4). This indicates the improved voltage profile with RE and FACTS devices in the network and consequently enhanced stability, reduced losses.

Comparison of different algorithms in terms of overall objective functions for scenario 5: case (a) and case (b) is given in Fig. 5 and Fig. 6, respectively. In both the cases, ACSA is outperformed than other algorithms with lowest overall objective function value and less computational time. 


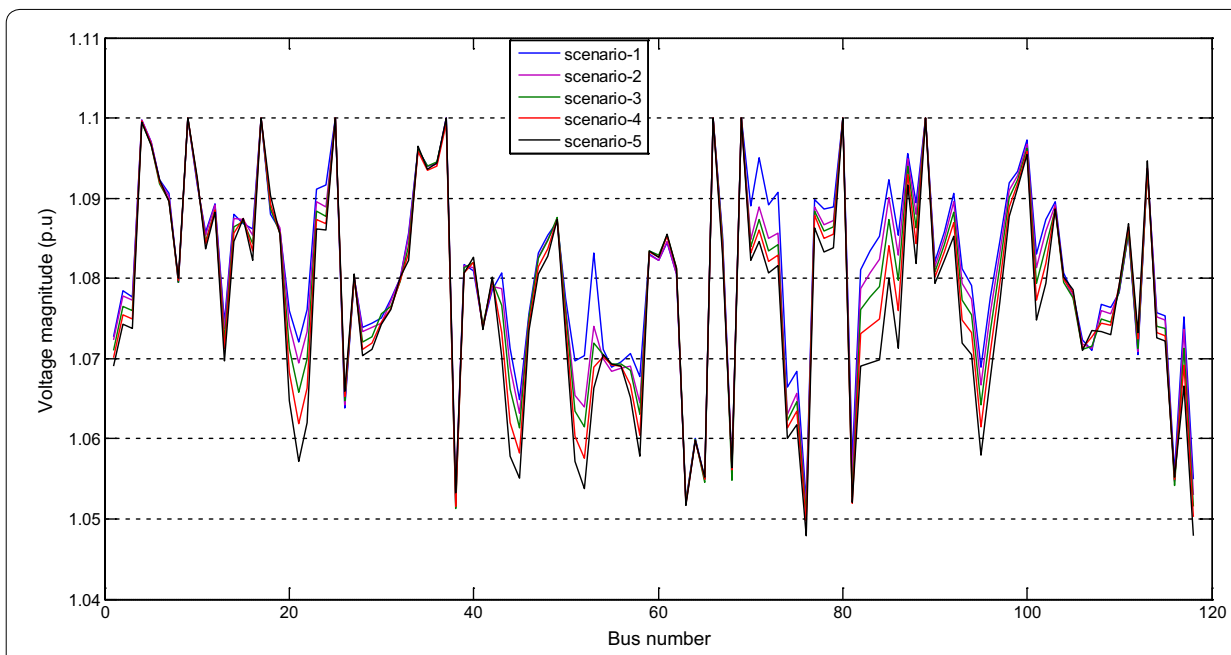

Fig. 4 Voltage profile for case (b) under different scenarios using ACSA in 118-bus system

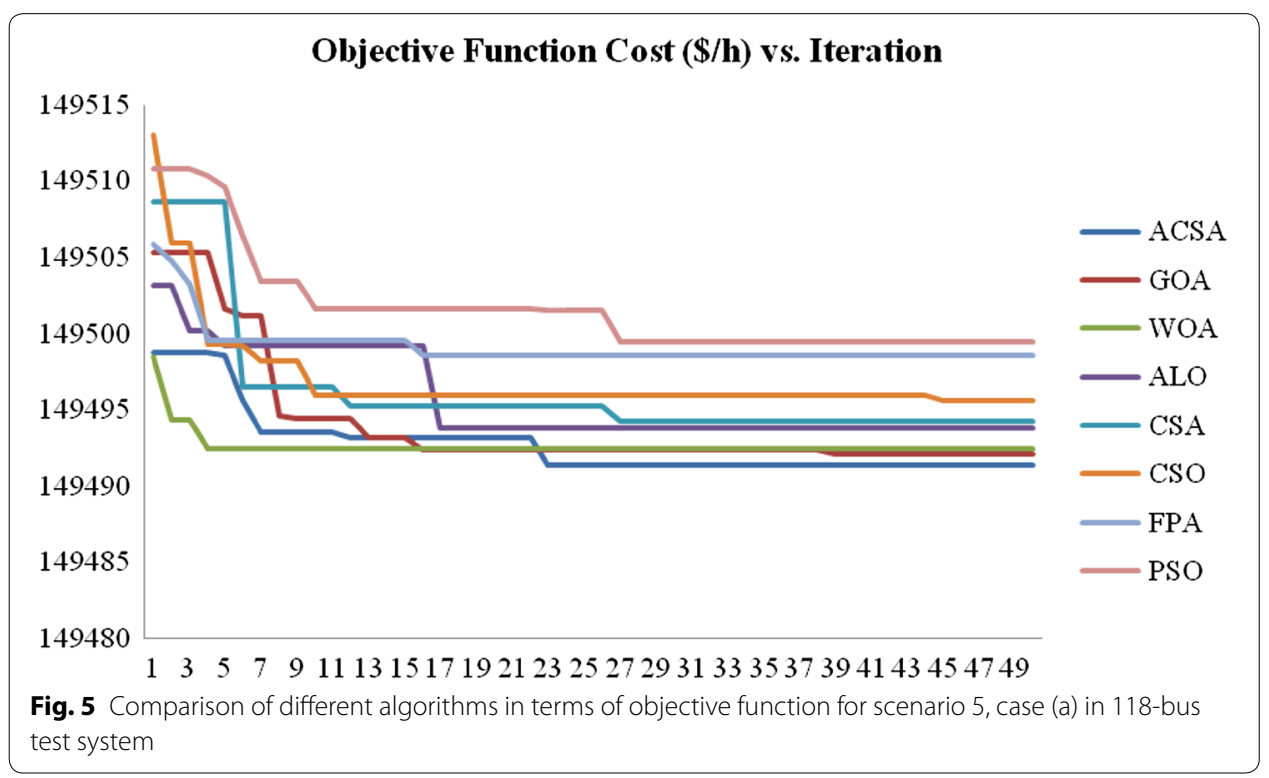

\section{Conclusion}

In this paper, the impact of changing weather conditions on transmission system parameters, PV generation and loading profile are modeled considering the effect of ambient temperature and analyzed w.r.t. power system economic operation. In order to overcome the transmission system dispatchable problems for economic schedule, optimal unified power flow controller (OUPFC) is proposed to integrate optimally in the system. Primarily the location of OUPFC is determined using voltage collapse point indicator (VCPI) and its controlling variables involved in power injection modeling and various system operating constraints are optimized. A multi-objective function is formulated to minimize operating cost, real power losses, average voltage collapse point indicator and average voltage deviation index and solved using adaptive cuckoo search algorithm 


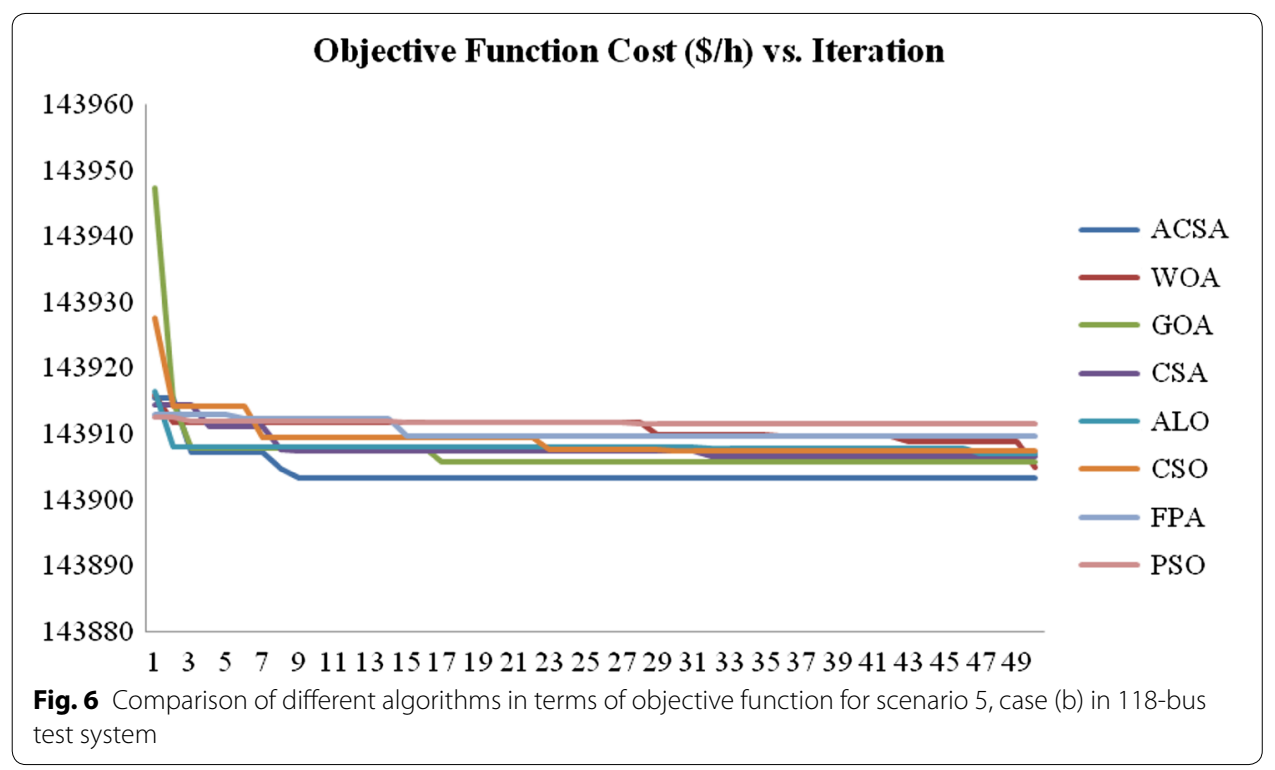

(ACSA), in which the switching parameter is adjusted in a power of three for adjusting the random walk between local optima and global optima. The simulation studies are performed on IEEE 14-, 30- and 118-bus test systems for five different weather changing conditions. From the simulations, it is observed that the increasing ambient temperature caused to increase the resistance of the transmission lines, load profile and decrease in solar PV generation. Also, causes to increase real power losses, decrease stability margin and voltage profile. Later, the techno-economic performance of the system is improved by having optimal controls of OUPFC. Also, the performance of ACSA is compared with basic CSA, PSO, CAO, FPA, GHO, WOA and ALO. From the results obtained, ACSA is outperformed over other algorithms by providing the best objective function values with less computational time. Also, the proposed hybrid approach of economic schedule, OUPFC controls and PV generation are resulted for improving the stability margin, voltage profile and reducing the real power losses, which can adoptable for coping-up the futuristic weather changes. In view of increasing trend of RE share in power generation and changing ambient temperature conditions, the modern power system economics and security margins with different types of FACTS devices are still need to optimize under normal and contingency cases and treated as the future scope of this work.

\section{Abbreviations}

FACTS: flexible AC transmission systems; OUPFC: optimal unified power flow controller; ACSA: adaptive cuckoo search algorithm; PSO: particle swarm optimization; CSO: chicken swarm optimization; FPA: flower pollination algorithm; GHO: grasshopper optimization algorithm; WOA: whale optimization algorithm; ALO: ant lion optimization; VCPI: voltage collapse point indicator; RES: renewable energy sources.

\section{Author's contributions}

KVKK carried out the literature survey and participated in determining the optimal location of OUPFC based on voltage collapse point indicator (VCPI). KVKK and PVRLN participated in study on the different nature-inspired algorithms and among those ACSA, basic CSA, PSO, CSO and FPA algorithms are considered for this paper. KVKK carried the simulations under two different scenarios such as different weather conditions and load growth conditions for standard test systems and the results were compared under different algorithms. KVKK and PVRLN participated in the sequence of alignment and drafted the manuscript. Both together read and approved the final manuscript.

\section{Funding}

The authors have no funding source. 


\section{Availability of data and material}

The authors of the papers used the data available at the below reference.

R. D. Zimmerman, C. E. Murillo-Sanchez, and R. J. Thomas. (2011), "MATPOWER: Steady-State Operations, Planning and Analysis Tools for Power System Research and Education," IEEE Transactions on Power Systems, Vol. 26, No. 1, pp. $12-19$.

\section{Competing interests}

(1) Optimal location optimal unified power flow controller (OUPFC) is proposed based on voltage collapse point indicator. (2) Dynamic switching parameter is proposed to the basic cuckoo search algorithm (CSA) for solving the complex and multi-objective optimization problem. (3) Simulations are analyzed for different weather conditions and load growth scenarios, and each scenario is repeated for two case studies (a) without considering PV systems and OUPFC in the network and (b) considering PV systems and OUPFC in the network. (4) The effectiveness of the proposed adaptive CSA approach for solving the OPF problem including OUPFC is illustrated using standard IEEE 14, 30 and 118-bus systems and compared with basic CSA, PSO, CSO and FPA.

\section{Author details}

${ }^{1}$ Research Scholar, Department of Electrical and Electronics Engineering, JNTUK, Kakinada, Andhra Pradesh 533003, India. ${ }^{2}$ Department of Electrical and Electronics Engineering, V R Siddhartha Engineering College, Vijayawada, Andhra Pradesh 520007, India.

Received: 26 January 2020 Accepted: 17 June 2020

Published online: 01 July 2020

\section{References}

1. Jennings P (2009) New directions in renewable energy education. Renew Energy 34(2):435-439. https://doi. org/10.1016/j.renene.2008.05.005

2. Hvelplund F (2006) Renewable energy and the need for local energy markets. Energy 31(13):2293-2302. https://doi. org/10.1016/j.energy.2006.01.016

3. Renewable energy statistics (2019) ISBN: 9780.00920 .0092600 .001370 .009 by International Renewable Energy Agency (IRENA). www.irena.org. Accessed 1 July 2019

4. Alrikabi NKMA (2014) Renewable Energy Types. Journal of Clean Energy Technologies 2(1):61-64. https://doi. org/10.7763/JOCET.2014.V2.92

5. Petinrin OJ, Shaaban M (2012) Overcoming challenges of renewable energy on future smart grid. TELKOMNIKA Indones J Electr Eng 10(2):229-234. https://doi.org/10.11591/telkomnika.v10i2.675

6. Atputharajah A, Saha TK (2009) Power system blackouts-literature review. In: 2009 international conference on industrial and information systems (ICIIS), Sri Lanka, pp 460-465. https://dx.doi.org/10.1109/ICIINFS.2009.5429818

7. Adibi MM (2015) Impact of power system blackouts. In: 2015 IEEE power \& energy society general meeting, Denver CO, July 2015. https://dx.doi.org/10.1109/PESGM.2015.7286025

8. Kang T et al (2017) A hybrid approach for power system security enhancement via optimal installation of flexible AC transmission system (FACTS) devices. Energies 10(9):1305. https://doi.org/10.3390/en10091305

9. Abido MA (2009) Power system stability enhancement using FACTS controllers: a review. Arab J Sci Eng 34(1B):153-172

10. Kumar A, Srivastava SC, Singh SN (2005) Congestion management in competitive power market: a bibliographical survey. Electric Power Syst Res 76(1):153-164. https://doi.org/10.1016/j.epsr.2005.05.001

11. Zhang W, Li F, Tolbert LM (2007) Optimal allocation of shunt dynamic VAr source SVC and STATCOM: a survey. IEEE Trans Power Syst. https://doi.org/10.1049/cp:20062251

12. Wood AJ, Wollenberg BF, Sheble GB (2013) Power generation, operation and control, 3rd edn. Wiley, Hoboken

13. Shilaja C, Arunprasath $T$ (2019) Optimal power flow using moth swarm algorithm with gravitational search algorithm considering wind power. Future Generation Comput Syst 10:15-20. https://doi.org/10.1016/j.futur e.2018.12.046

14. Elattar EE (2019) Optimal power flow of a power system incorporating stochastic wind power based on modified moth swarm algorithm. IEEE Access 7:89581-89593. https://doi.org/10.1109/ACCESS.2019.2927193

15. Duman Serhat, Li Jie, Lei Wu, Guvenc Ugur (2019) Optimal power flow with stochastic wind power and FACTS devices: a modified hybrid PSOGSA with chaotic maps approach. Neural Comput Appl. https://doi.org/10.1007/ s005210.000190.00043380.00y

16. Sang Y, Sahraei-Ardakani M (2019) Effective power flow control via distributed FACTS considering future uncertainties. Electric Power Syst Res 168:127-136. https://doi.org/10.1016/j.epsr.2018.11.017

17. El-Fergany AA, Hasanien HM (2018) Tree-seed algorithm for solving optimal power flow problem in large-scale power systems incorporating validations and comparisons. Appl Soft Comput 64:307-316. https://doi.org/10.1016/j asoc.2017.12.026

18. Elattar EE, EISayed SK (2019) Modified JAYA algorithm for optimal power flow incorporating renewable energy sources considering the cost, emission, power loss and voltage profile improvement. Energy 178:598-609. https:// doi.org/10.1016/j.energy.2019.04.159

19. Shilaja C, Ravi K (2017) Optimal power flow using hybrid DA-APSO algorithm in renewable energy resources. Energy Procedia 117:1085-1092. https://doi.org/10.1016/j.egypro.2017.05.232

20. Nguyen TT (2019) A high performance social spider optimization algorithm for optimal power flow solution with single objective optimization. Energy 171:218-240. https://doi.org/10.1016/j.energy.2019.01.021

21. Attia AF, El Sehiemy RA, Hasanien HM (2018) Optimal power flow solution in power systems using a novel SineCosine algorithm. Int J Electr Power Energy Syst 99:331-343. https://doi.org/10.1016/j.ijepes.2018.01.024 
22. Luo J, Shi L, NiY (2018) A solution of optimal power flow incorporating wind generation and power grid uncertainties. IEEE Access 6:19681-19690. https://doi.org/10.1109/ACCESS.2018.2823982

23. Huang S, Dinavahi V (2018) Fast batched solution for real-time optimal power flow with penetration of renewable energy. IEEE Access 6:13898-13910. https://doi.org/10.1109/ACCESS.2018.2812084

24. Duman S (2018) A modified moth swarm algorithm based on an arithmetic crossover for constrained optimization and optimal power flow problems. IEEE Access 6:45394-45416. https://doi.org/10.1109/ACCESS.2018.2849599

25. Shaheen MA, Hasanien HM, Mekhamer SF, Talaat HE (2019) Optimal power flow of power systems including distributed generation units using sunflower optimization algorithm. IEEE Access 7:109289-109300. https://doi. org/10.1109/ACCESS.2019.2933489

26. Singh RP, Mukherjee V, Ghoshal SP (2015) Particle swarm optimization with an aging leader and challengers algorithm for optimal power flow problem with FACTS devices. Int J Electr Power Energy Syst 64:1185-1196. https://doi. org/10.1016/j.jijepes.2014.09.005

27. Verma S, Saha S, Mukherjee V (2017) A novel symbiotic organisms search algorithm for congestion management in deregulated environment. J Exp Theor Artif Intell 29(1):59-79. https://doi.org/10.1080/0952813X.2015.1116141

28. Chaib AE, Bouchekara HREH, Mehasni R, Abido MA (2016) Optimal power flow with emission and non-smooth cost functions using backtracking search optimization algorithm. Electr Power and Energy Syst 81:64-77. https://doi. org/10.1016/j.jiepes.2016.02.004

29. Parouha RP, Das KN (2016) A novel hybrid optimizer for solving economic load dispatch problem. Int J Electr Power Energy Syst 78:108-126. https://doi.org/10.1016/j.ijepes.2015.11.058

30. Pandiarajan K, Babulal CK (2016) Fuzzy harmony search algorithm based optimal power flow for power system security enhancement. Electr Power and Energy Syst 78:72-79. https://doi.org/10.1016/j.ijepes.2015.11.053

31. Prasad D, Mukherjee V (2016) A novel symbiotic organisms search algorithm for optimal power flow of power system with FACTS devices". Engineering Science and Technology, an International Journal 19:79-89. https://doi. org/10.1016/j.jestch.2015.06.005

32. Vijay Kumara YN, Sivanagaraju S, Suresh CV (2016) Analyzing the effect of dynamic loads on economic dispatch in the presence of interline power flow controller using modified BAT algorithm. J Electr Syst Inf Technol 3(4567):2016. https://doi.org/10.1016/j.jesit.2015.08.003

33. Ghiasi M (2019) Detailed study, multi-objective optimization, and design of an AC-DC smart microgrid with hybrid renewable energy resources. Energy 169:496-507

34. Ghiasi M (2019) Technical and economic evaluation of power quality performance using FACTS devices considering renewable generations. Renew Energy Focus 29:49-62

35. Momoh JA, Adapa R, El-Hawary ME (1999) A review of selected optimal power flow literature to 1993. I. nonlinear and quadratic programming approaches. IEEE Trans Power Syst 14(1):96-104. https://doi.org/10.1109/59.744492

36. Momoh JA, El-Hawary ME, Adapa R (1999) A review of selected optimal power flow literature to 1993. II. Newton, linear programming and interior point methods. IEEE Trans Power Syst 14(1):105-111. https://doi. org/10.1109/59.744495

37. Torres GL, Quintana VH (1998) An interior-point method for nonlinear optimal power flow using voltage rectangular coordinates. IEEE Trans Power Syst 13(4):1211-1218. https://doi.org/10.1109/59.736231

38. Chen CS, Kang MS, Hwang JC, Huang CW (2001) Temperature effect to distribution system load profiles and feeder losses. IEEE Trans Power Syst 16(4):916-921. https://doi.org/10.1109/59.962446

39. Lin CH et al (2006) Temperature effect to distribution feeder load profiles and losses. In: 2006 international conference on power system technology, chongqing, 2006, pp 1-7. http://dx.doi.org/10.1109/ICPST.2006.321962

40. Al-Ammar EA, Ghazi GA, Ko W (2018) Impact of ambient temperature on shunt capacitor placement in a distorted radial distribution system. Energies 11(6):1585. https://doi.org/10.3390/en11061585

41. Ahmed F, McFadden S, Rayudu R (2008) Transient stability study incorporating weather effects on conductors. In: 2018 IEEE power \& energy society general meeting (PESGM), Portland, OR, 2018, pp 1-5. https://doi.org/10.1109/ PESGM.2018.8586432

42. Frank S, Sexauer J, Mohagheghi S (2013) Temperature-dependent power flow. IEEE Trans Power Syst 28(4):4007-4018

43. Ahmed A, McFadden FJS, Rayudu R (2019) Weather-dependent power flow algorithm for accurate power system analysis under variable weather conditions. IEEE Trans Power Syst 34(4):2719-2729. https://doi.org/10.1 109/tpwrs .2019 .2892402

44. Zhang Z (2018) Influence of special weather on output of PV system. IOP Conf Ser Earth Environ Sci 108:052063

45. Ghazi S, I I K (2014) The effect of weather conditions on the efficiency of PV panels in the southeast of UK. Renew Energy 69:50-59. https://doi.org/10.1016/.j.renene.2014.03.018

46. Burillo Daniel (2018) Effects of climate change in electric power infrastructures. Power Syst Stab. https://doi. org/10.5772/intechopen.82146

47. Mareli M, Twala B (2018) An adaptive Cuckoo search algorithm for optimisation. Appl Comput Inform 14(2):107-115. https://doi.org/10.1016/j.aci.2017.09.001

48. Ara A, Kazemi Lashkar A, Nabavi Niaki SA (2011) Modelling of Optimal Unified Power Flow Controller (OUPFC) for optimal steady-state performance ofpower systems. Energy Convers Manage 52(2):1325-1333

49. Bansal RC (2005) Optimization methods for electric power systems: an overview. Int J Emerg Elec Power Syst 2(1)

50. Gaur Dipesh, Mathew Lini (2018) Optimal placement of FACTS devices using optimization techniques: A review. IOP Conference Series: Materials Science and Engineering 331(012023):1-16

51. Jafarzadeh J, Haq MT, Mahaei SM, Farhadi P. Optimal placement of FACTS devices based on network security. In: 3rd International Conference on Computer Research and Development (ICCRD). 2011; pp. 345-349

52. Rekioua D, Ernest M. Modeling of solar irradiance and cells. In: Optimization of Photovoltaic Power Systems. Springer London, 2012, XII, p 284

53. IEEE Standard Test Code for Dry-Type Distribution and Power Transformers, IEEE Std. C57.12.91, 2001.

54. X.-S. Yang, Nature -Inspired Optimization algorithms, First ed., London: Elsevier, 2014 
55. Civicioglu P, Besdok E (2013) A conceptual comparison of the Cuckoo-search, particle swarm optimization, differential evolution and artificial bee colony algorithms. Art Intel Rev 39(4):315-346

56. Zheng H, Zhou Y (2012) A novel cuckoo search algorithm based on Gauss distribution. J Comput Inform Syst 8(10):4193-4200

57. Zaw MM, Mon EE (2014) Web document clustering using Gauss distribution based cuckoo search clustering algorithm. Int J Sci Eng Technol Res 3(13):2945-2949

58. Ho SD, Vo VS, Le TM, Nguyen TT (2014) Economic emission load dispatch with multiple fuel optings using cuckoo search algorithm with Gaussian and Cauchy distributions. Int J Energy, Inform Communi 5(5):39-54

59. Nguyen TT, Vo DN, Dinh BH (2016) Cuckoo search algorithm using different distributions for short term hydrothermal scheduling with reservoir volume constraint. Int J Elec Eng Inform 8(1):76-92

60. Roy S, Mallick A, Chowdhury SS, Roy S (2015) A novel approach on cuckoo search algorithm using Gamma distribution. In: Second international conference on electronics and communication systems, 2015

61. Tusiy SI, Shawkat N, Ahmed MA, Panday B, Sakib N (2015) Comparative analysis on improved cuckoo search algorithm and artificial bee colony algorithm on continuous optimization problems. Int J Adv Res Artificial Intelligence 4(2):14-19

62. Tuba M, Subotic M, Stanarevic N (2011) Modified Cucko search algorithm for unconstrained optimization problems. In: Proceedings of the European Computing Conference, 2011

63. Fister Jl, Dušan F, Iztok F (2013) A comprehensive review of cuckoo search: variants and hybrids. Int J Mathe Model Num Optim 4(4):387-409

64. Zimmerman RD, Murillo-Sanchez CE, Thomas RJ (2011) MATPOWER: steady-state operations, planning and analysis tools for power system research and education. IEEE Trans Power Syst 26(1):12-19

65. http://www.greenice.in/download/Datasheet\%20-\%20TP250.pdf. Accessed 24 June 2020

\section{Publisher's Note}

Springer Nature remains neutral with regard to jurisdictional claims in published maps and institutional affiliations.

\section{Submit your manuscript to a SpringerOpen ${ }^{\odot}$ journal and benefit from:}

- Convenient online submission

- Rigorous peer review

- Open access: articles freely available online

- High visibility within the field

- Retaining the copyright to your article

Submit your next manuscript at $\mathbf{s p r i n g e r o p e n . c o m ~}$ 